\title{
Biomimetic supramolecular designs for the controlled release of growth factors in bone regeneration 2
}

\author{
Helena S. Azevedo ${ }^{\mathrm{a}, \mathrm{b}}$, Iva Pashkuleva ${ }^{\mathrm{c}, \mathrm{d}}$ \\ a School of Engineering and Materials Science, Queen Mary University of London, Mile End Road, London E1 4NS, UK \\ b Institute of Bioengineering, Queen Mary University of London, Mile End Road, London E1 4NS, UK

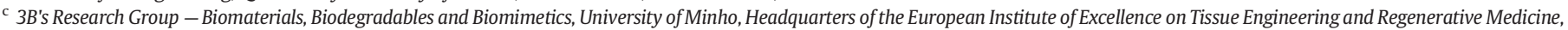 \\ AvePark, 4805-017 Barco Guimarães, Portugal \\ d ICVS/3B's - PT Government Associate Laboratory, Braga/Guimarães, Portugal
}

\section{A R T I C L E I N F O}

\section{Article history:}

Received 8 December 2014

Received in revised form 17 August 2015

Accepted 25 August 2015

Available online 29 August 2015

\section{Keywords:}

Extracellular matrix

Glycosaminoglycans

Growth factors

Molecular recognition

Multivalent interactions

Biomimetic

Self-assembly

Peptides

\begin{abstract}
A B S T R A C T
The extracellular matrix (ECM) of tissues is an assembly of insoluble macromolecules that specifically interact with soluble bioactive molecules and regulate their distribution and availability to cells. Recapitulating this ability has been an important target in controlled growth factor delivery strategies for tissue regeneration and requires the design of multifunctional carriers. This review describes the integration of supramolecular interactions on the design of delivery strategies that encompass self-assembling and engineered affinity components to construct advanced biomimetic carriers for growth factor delivery. Several glycan- and peptide-based self-assemblies reported in the literature are highlighted and commented upon. These examples demonstrate how molecular design and chemistry are successfully employed to create versatile multifunctional molecules which self-assemble/ disassemble in a precisely predicted manner, thus controlling compartmentalization, transport and delivery. Finally, we discuss whether recent advances in the design and preparation of supramolecular delivery systems have been sufficient to drive real translation towards a clinical impact.
\end{abstract}

(c) 2015 Elsevier B.V. All rights reserved.

\section{Contents}

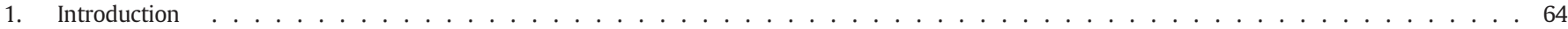

2. Growth factors $(\mathrm{GFs})$ involved in bone regeneration . . . . . . . . . . . . . . . . . . . . . . . . . 65

3. Extracellular matrix $(\mathrm{ECM})$ as a depot for $\mathrm{GFs} \ldots \ldots \ldots \ldots$

3.1. Dynamics and signalling . . . . . . . . . . . . . . . . . . . . . . . . . . . . . . . 65

3.2. Molecular recognition . . . . . . . . . . . . . . . . . . . . . . . . . . . 65

4. Supramolecular strategies for the controlled release of GFs using peptides and glycosaminoglycans (GAGs) . . . . . . . . . . . . . . . . . . . . 65

4.1. Self-assembly approaches to design peptide-based carriers . . . . . . . . . . . . . . . . . . . . . . . . . . 66

4.1.1. Molecular design . . . . . . . . . . . . . . . . . . . . . . . . . . . . . . . . 66

4.1.2. Engineering release patterns . . . . . . . . . . . . . . . . . . . . . . . . . . 67

4.2. Self-assembly and peptide functionalization approaches to control retention and presentation of GFs . . . . . . . . . . . . . . . . 68

4.3. Polyelectrolyte complexation approaches to design GAG-based carriers . . . . . . . . . . . . . . . . . . . . . . . 70

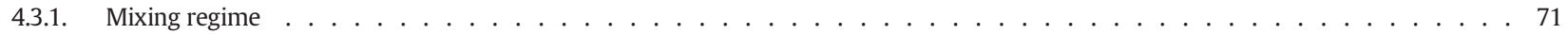

4.3.2. Macromolecular characteristics of the polyelectrolytes . . . . . . . . . . . . . . . . . . . . . . . . . 71

4.3.3. Medium conditions . . . . . . . . . . . . . . . . . . . . . . . . . . 72

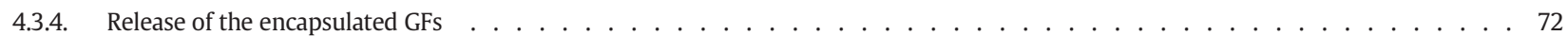

4.3.5. Micellar delivery systems based on block co-polymers . . . . . . . . . . . . . . . . . . . . . . . . . . . 73

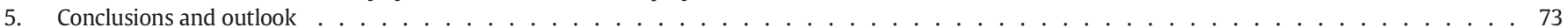

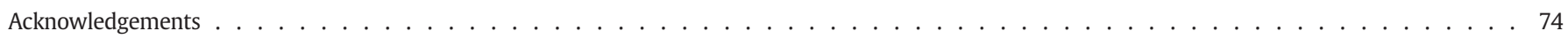

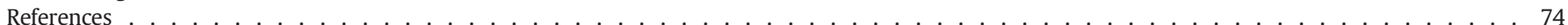

is This review is part of the Advanced Drug Delivery Reviews theme issue on "Drug delivery to bony tissue".

E-mail addresses: h.azevedo@qmul.ac.uk (H.S. Azevedo), pashkuleva@dep.uminho.pt (I. Pashkuleva). 


\section{Introduction}

Less invasive therapies, that can mediate repair and regeneration of a variety of damaged tissues and provide faster and more efficient healing responses, are currently major clinical targets. In response to this pharmaceutical challenge, drug delivery systems have evolved tremendously during the past years. Current research in the area is focused on the development of multifunctional and stimuli-sensitive systems that can perform multiple functions (simultaneously or sequentially) and overcome diverse physiological barriers to optimize delivery to target sites (organs, tissues, cells) (Fig. 1A) [1].

Considering the importance of growth factors (GFs) in tissue regeneration, delivery of these molecules into damaged/degenerated tissues has become an obvious strategy to enhance the healing process. Their direct injection, or systematic local supplementation, results in lower availability of the GFs because generally these molecules have a short half-life in circulation (up to several minutes) due their rapid degradation in vivo $[3,4]$. On the other hand, tissues need to be exposed to gradients of these proteins for considerable periods (long-acting) to obtain robust regenerative responses. In vivo, this problem is solved by protection and stabilization of the GF via their binding to different extracellular matrix (ECM) components. As a result, matrix-bound GFs are more effective than their soluble counterparts. In a similar manner, materials designed to bind soluble GFs can be used to control protein concentration locally and regulate GF signalling. Inspired by the native environment of GFs, the ECM, researchers have proposed different selfassembly approaches that mimic the supramolecular interactions within the ECM for the design and development of sophisticated delivery systems with higher stability and specificity. Because self-assembly can be triggered at a desired place and time, self-assembling carriers offer a unique approach for the controlled release of bioactive and therapeutic molecules. While self-assembled nanocarriers (micelles, liposomes, vesicles, tubes) have been widely used for the delivery of small drugs [5], the supramolecular presentation of bioactive macromolecules such as proteins is more challenging. The sequestering of specific or multiple proteins can be done by the integration of bioactive molecular components that have selective or broad affinity to the targeted GFs into the self-assembling carriers. However, the incorporation of these functionalities into self-assembling carriers, and the subsequent binding of large molecules (e.g. proteins), may disturb their selfassembly. In addition, integration of complex functionalities can lead to difficulties in their synthesis, posing scale-up problems for manufacture and translation into the clinic. Recognizing these challenges, researchers have been using bioinspired designs to recreate the natural extracellular environment for controlling the co-localization and release of proteins.

In this review, we begin by introducing GFs relevant to bone regeneration and the role of the ECM in the control of GF signalling. We then describe different carrier systems, inspired by the molecules and interactions present in the ECM, with a special focus on peptide selfassembly and polyelectrolyte complexation. We give a brief overview on how these carriers can be engineered (through rational molecular design) and manipulated (by changing their assembly environment) to control the encapsulation and release of molecules of interest. The purpose is to provide supramolecular elements for the molecular design of carriers for GF delivery. Finally, we provide key examples of supramolecular strategies that have been used to construct carriers and control the release of GFs involved in bone regeneration.
A

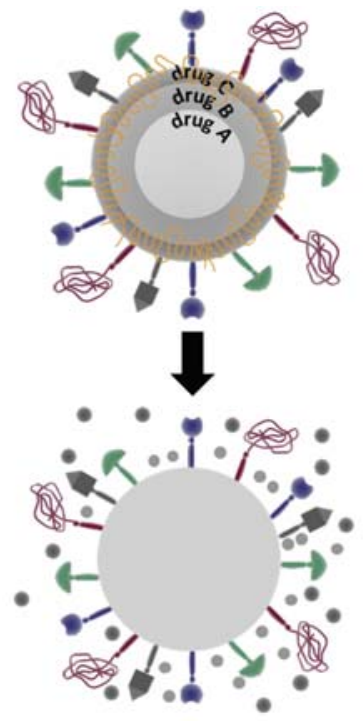

Hydrophilic polymer (e.g. PEG to

increase long circulation)

Targeting agent (e.g. antibody, peptides)

Imaging or contrast agent

Cell penetrating peptide for intracelllular delivery

Sensitive moiety $(\mathrm{pH}$, temperature, enzyme activity)

Drug $A, B, C$
B

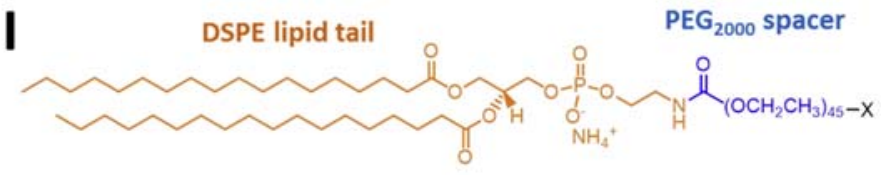

II

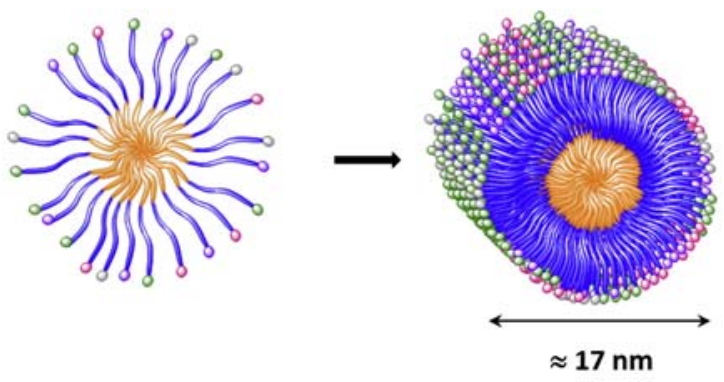

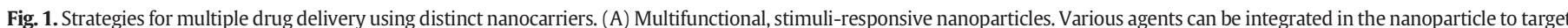

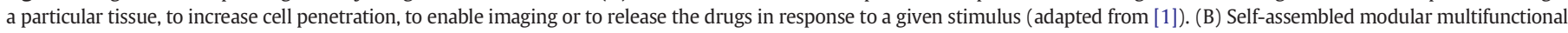

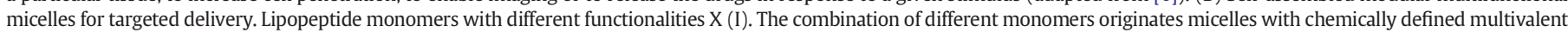
ligands (II) (adapted from [2]). 


\section{Growth factors (GFs) involved in bone regeneration}

GFs are large polypeptides that modulate cellular activities such as adhesion, proliferation, migration, differentiation and gene expression [6]. They are activated by binding to specific receptors on the surface of target cells and the density of these receptors largely reflects the cell response. GFs can either be found as bound proteins to the ECM or as soluble molecules secreted by cells. The activity of bone cells is modulated by several families of GFs (Table 1). Among them, the cytokines BMP-2 and BMP-7 from the family of bone morphogenetic proteins (BMPs) have been approved by FDA and are used clinically. INFUSE $®$ Bone Graft is an US FDA approved commercially available carrier, based on a sponge of bovine collagen type I, used for the delivery of recombinant human BMP-2 (rhBMP-2) to stimulate bone formation in orthopaedic and dental applications. The carrier sponge localizes the rhBMP-2 at the site of implantation and resorbs over time.

Delivery of GFs can either be done using the GF free within the carrier (physical entrapment) or bound to it through a covalent linkage or non-covalent interactions. The selection of the immobilization method depends on the GF itself and/or the delivery strategy/application [6]. GF immobilization methods, as well as their advantages and limitations, have been described in several reviews [6-8].

\section{Extracellular matrix (ECM) as a depot for GFs}

The ECM is a unique structural support for organs and tissues as well as for individual cell attachment, differentiation, proliferation and migration. It is well established that its mechanical properties influence significantly the cellular behaviour [20-22]. The role of the ECM, however, goes far beyond just being a simple supporting scaffold [23]: it provides significant biochemical information displayed via the molecules secreted by the cells, i.e. it is unique for each cell. Many soluble factors, including GFs, are secreted by cells and entrapped in the ECM where they are stored (stabilized and protected from denaturation and enzymatic degradation [24]), distributed and/or activated [23,25,26]. ECM components are thus acting as local regulators of GF activity. Because the ECM itself is a dynamic structure, all ECM-GFs interactions are also dynamic, reversible and orchestrated by multivalent non-covalent interactions.

\subsection{Dynamics and signalling}

Cells constantly remodel the ECM by degrading and reassembling it, and this process is particularly intensive during tissue development and healing [27]. During the remodelling process, the ECM chemical composition (degradation of ECM components such as proteins and glycans) and physical properties (elasticity, stiffness, resilience of the cellular environment) are significantly altered [28]. The remodelling of the ECM is poorly understood as it is controlled by complex signal transduction cascades involving many proteins, but it is well established that integrins are crucial players in this process as they are the main mean of communication between cells and their closest environment [29]. Glycosaminoglycans (GAGs) are other ECM components that are constantly changing during the processes of differentiation and healing. As an example, they play crucial role in the formation of stem cell niches - specific microenvironments that save stem cells from depletion and protect the host from over-exuberant stem cell proliferation. Stem cell niches are distinguished by the presence of low sulfated GAGs [30,31], whose role is to avoid exposure of stem cells to GF and receptor binding and thus to maintain them in undifferentiated state. When daughter cells are translocated outside the niche, they are no longer protected by this shield and exposed to proteins that activate different signalling pathways and hence compelling processes such as proliferation and differentiation. Loss of pluripotency and differentiation are accompanied with changes in the sulfation pattern of GAGs in the ECM: drop in the level of non-sulfated disaccharides and increase in the sulfation is observed upon differentiation of human stem cells in different lineages [31].

\subsection{Molecular recognition}

Among the ECM components, proteins and their glycoconjugates (proteoglycans and glycoproteins) are mostly involved in the interactions with GFs $[32,33]$. Heparan sulfate proteoglycans (HSPG) are the best studied pairs for GFs binding [34]. HS is a linear GAG that is negatively charged due to the numerous sulfate groups along its backbone. These sulfate groups serve as multiple contacts to positively charged regions in proteins and GFs (made up of clusters of basic amino acids). The linear structures of GAGs restrict movement of bound proteins to one dimension in the three-dimensional space, facilitating intercellular communication (both paracrine and endocrine signalling) over these molecular wires. The interactions between GFs and GAGs are specific, involving formation of highly organized complexes of two or often more than two macromolecules. An excellent example that illustrates this orchestrated self-assembly process is the activation of basic fibroblast growth factor (FGF-2) for which formation of a tight ternary complex between the GF, HS and the receptor for the growth factor (FGFR) is required (Fig. 2) [35-37]. FGF-2 alone has high affinity to HS [36]: the interaction occurs via the pentasaccharide (Fig. 2A) as soon as the GF is secreted by the cells (Fig. 2B-I). As a result, FGF-2 is immobilized in the ECM, near to the site of secretion, where it is stored and protected against degradation until further use [24]. The activation of the stored FGF-2 is done also by HS, but in this case a longer (10 mer) sequence is required [38]. This longer sequence binds to both FGF-2 and FGFR in a ternary complex (Fig. 2B-II). The obtained minimal complex is further stabilized by dimerization that is also promoted by HS (Fig. 2B-III). Besides FGF, other bone-related GFs such as TGF- $\beta$ [39], VEGF [40-42], IGF $[43,44]$ and/or their receptors also interact specifically with HSPG.

This review is focussed on biomimetic supramolecular (non-covalent) interactions to build carriers from peptides and GAGs, and to control the binding and release of different GFs, recapitulating the function of the ECM.

\section{Supramolecular strategies for the controlled release of GFs using peptides and glycosaminoglycans (GAGs)}

Using self-assembly and a variety of building blocks (nucleotides, saccharides, phospholipids, amino acids), Nature not only organizes macromolecules into hierarchically ordered structures and tissues, but also coordinates many molecular recognition processes. Peptide and protein self-assembly is a well-studied phenomenon in chemistry and biology, where their peptide chains self-associate into well-defined

Table 1

Main families of GFs that are involved in bone development.

\begin{tabular}{|c|c|c|c|}
\hline GF family & Abbreviation & Role in bone physiology & Ref \\
\hline Fibroblast growth factors & FGF & Growth and patterning of the limb, bone homeostasis, differentiation of BMSC into osteoblasts & [9-11] \\
\hline Bone morphogenic proteins & BMP & Bone, limb and cartilage morphogenesis and development; involvement in the osteoblasts differentiation & {$[12,13]$} \\
\hline Vascular endothelial growth factors & VEGF & Critical role in bone formation by controlling the recruitment, survival and activity of bone forming cells & {$[14,15]$} \\
\hline Insulin-like growth factors & IGF & $\begin{array}{l}\text { Most abundant GFs in the skeletal tissues; involved in osteoblasts proliferation, bone matrix synthesis } \\
\text { and bone resorption }\end{array}$ & [16-18] \\
\hline Transforming growth factor- $\beta$ & TGF- $\beta$ & Tissue morphogenesis, cell proliferation and cell differentiation & [19] \\
\hline
\end{tabular}


A
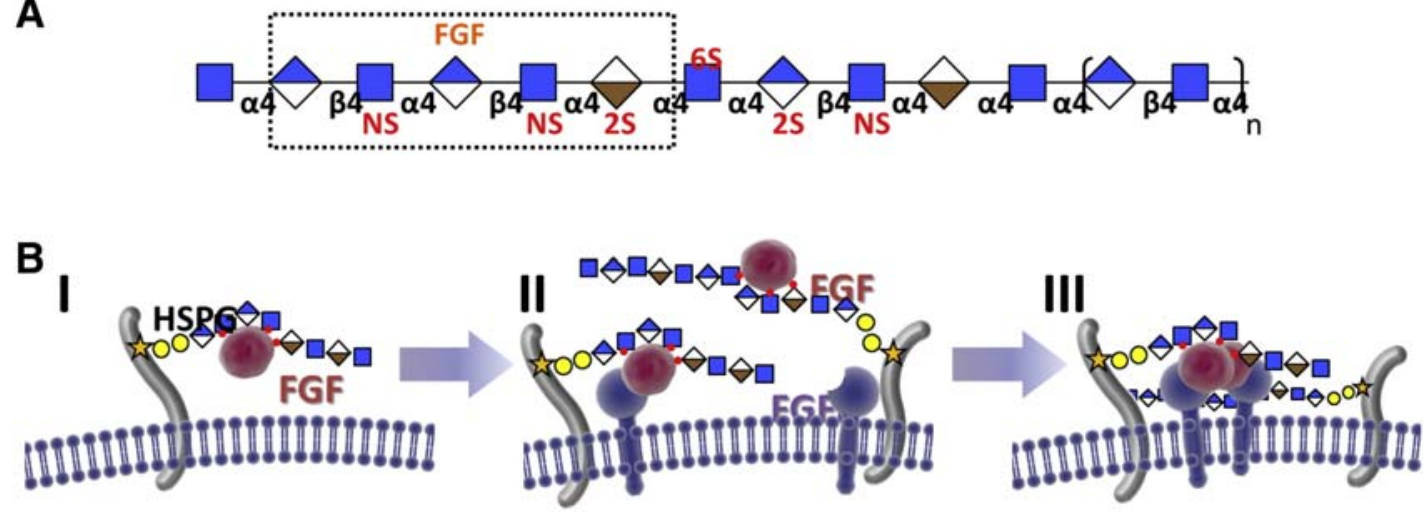

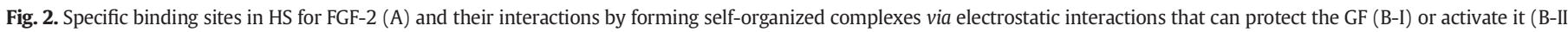
and III).

functional structures through non-covalent forces (electrostatic interactions, hydrogen bonds, aromatic interactions, van der Waals forces and hydrophobic effects). Self-assembly offers several advantages to develop delivery carriers, such as simple route to fabricate complex systems, ease of incorporating multiple active units, tunability of nanostructure morphology and responsive nature. The reversibility of the assembly process, i.e. the disassembly, is also a consequence of the involvement of non-covalent interactions. As a result, self-assembly/disassembly can be triggered by an external or internal trigger ( $\mathrm{pH}$, temperature, enzyme activity) in spatial confinement. Thus, this methodology offers the possibility of incorporating different molecular guests (drugs, proteins) during the process of self-assembly and their release can be controlled through reversible structure transitions.

Beside proteins, other main components of the ECM are GAGs, which are native binding partners of GFs in the closest cellular environment. Therefore, they have also attracted great attention as a building element in self-assembling delivery systems $[45,46]$. GAGs are anionic polymers whose charge is generally associated with the presence of sulfate groups with only one exception - hyaluronic acid (hyaluronan, HA) in which the charge is due to the presence of carboxylic groups in the glucuronic acid sugar unit. Their negative charge is the main driving force for the self-assembly with GFs that have basic isoelectric points (e.g. all BMPs, TGF- $\beta$, FGF-2). Beside electrostatic interactions, hydrogen bonding can be also involved in the stabilization of the formed GF-GAG complexes. Delivery systems using GAGs as building blocks have several advantages: (i) they can stabilize the GFs during the self-assembly process and confine them with proper folding/conformation; (ii) protect the loaded GF from degradation; (iii) present minimal toxicity; (iv) offer the possibility for target delivery and optimization of the release profile.

\subsection{Self-assembly approaches to design peptide-based carriers}

Peptide molecules have been widely used as delivery carriers as they provide the possibility to form precise multivalent nanoarchitectures (micelles, vesicles, tubes, Fig. 1B). In addition, specific peptide sequences, that are recognized by cell surface integrins/receptors or enzymes, can be integrated into the peptide structure and thus afford further control of these modular assemblies to interact specifically and selectively with cells or tissues. For example, modular multifunctional micelles allow different functions to be incorporated into the same carrier (Fig. 1B). As such, peptide-based self-assembling systems (peptide amphiphiles, cyclic peptides, surfactant-like peptides, aromatic dipeptides, dendritic peptides) have been extensively studied as carriers for transport and delivery of different molecular drugs (oligonucleotides, hydrophobic chemotherapeutics) [47-51] into desired parts of the human body. Molecular design and manipulation of the environmental conditions can be useful strategies for controlling the release patterns of molecules of interest using these self-assembling peptide- based carriers. Most of the studies described below are fundamental and do not report the use of GFs, but model molecules. However, this class of carrier systems provides exquisite control over specific functionalization and release of encapsulated molecules, which may serve as a source of inspiration. Their inherent biocompatibility and biodegradability anticipate excellent prospects for their use in the controlled delivery of bioactive proteins like GFs.

\subsubsection{Molecular design}

It is well known that the sequence of amino acids in peptides dictates their secondary structure. Mutations of key amino acids, and/or changes of their position in the primary structure, have an impact on the intermolecular forces and dramatically change the morphology of peptide assemblies. This ability has been explored for controlled release applications.

Shi and colleagues [52] have developed choline mimicks (AdaGFFYKKK', Nap-GFFYKKK, Ada - adamantine, Nap - naphthaline, G glycine, $\mathrm{F}$ - phenylalanine, $\mathrm{Y}$ - tyrosine, $\mathrm{K}$ - lysine, $\mathrm{K}$ ' - lysine derivative by its quaternization) and demonstrated that their self-assembly can be directed into nanoparticles or nanofibres by simple change of the peptide capping group (Ada or Nap). Their study shows that self-assembly strategies can yield nanostructures with controllable multivalent architectures and anticipates the ability of these systems to selectively interact with GFs, if functionalized with specific peptide sequences (Table 2 ).

Zhao et al. [48] have shown that by changing the position of phenylalanine ( $\mathrm{F}$ ) in RADA peptides (RADAFI: $\mathrm{CH}_{3} \mathrm{CONH}-\mathrm{RADARADAR}$ FRADARADA-CONH${ }_{2}$, RADAFII: $\mathrm{CH}_{3} \mathrm{CONH}-\mathrm{RADFRADARARADARADA-}$ $\mathrm{CONH}_{2}$ ) different nanostructures are formed by self-assembly, from twisted nanofibres with varying diameter and length (RADAFI) to flat and uniform nanofibres (RADAFII). Through $\pi-\pi$ stacking, molecules with phenyl groups can be entrapped into the peptide RADAF selfassembled gels. The resulted distinct nanomorphologies play a role in the release of L-phenylalanine. This study elegantly shows the utility of supramolecular interactions for the incorporation of molecules within a self-assembled gel. Similarly, these nanofibres can contain specific functional groups on their surface to tether or capture GFs of interest, as described in Section 4.2.

Introduction of cysteine $(\mathrm{C})$ residues into the hydrophobic domain of a de novo amphiphilic peptide ( $\mathrm{SA} 2: \mathrm{CH}_{3} \mathrm{CONH}-\mathrm{A}_{2} \mathrm{~V}_{2} \mathrm{~L}_{3} \mathrm{WE}_{2}-\mathrm{CO}_{2} \mathrm{H}$ ), known to form nanosized vesicles under physiological conditions (SA2C3: $\mathrm{CH}_{3} \mathrm{CONH}-\mathrm{ACVCLCLWE}-\mathrm{CO}_{2} \mathrm{H}$ ), has allowed the formation of disulfide bridges and crosslinking of peptide vesicles for increasing their stability in vivo. Reduction of disulfide bonds intracellularly may assist the release of hydrophobic drugs.

A new type of self-assembling peptides for the delivery of molecular drugs, known as drug amphiphiles (DA), has been proposed by Cui and co-workers [53]. A typical DA combines a hydrophobic drug (e.g. 
Table 2

Examples of peptide sequences with binding affinity to GFs with relevance in bone regeneration for non-covalent immobilization and sustained release applications.

\begin{tabular}{|c|c|c|c|}
\hline GF & Binding peptide sequence & Applications & Ref. \\
\hline bFGF or FGF-2 & $\begin{array}{l}\text { KRTGQYKL Derived from phage display } \\
\left(K_{\mathrm{D}}=122 \mathrm{nM} \text {, estimated by SPR) }\right.\end{array}$ & $\begin{array}{l}\text { PEG hydrogels functionalized with binding peptide to bFGF allowed its sustained release and induced } \\
\text { in vitro differentiation of PC12 pheochromocytoma cell line in a gel-cell transwell culture system. }\end{array}$ & {$[78-80]$} \\
\hline BMP-2 & $\begin{array}{l}\text { TSPHVPY } \\
\text { Derived from phage display } \\
\left(\mathrm{K}_{\mathrm{D}}=37 \mathrm{nM} \text {, estimated by SPR }\right)\end{array}$ & $\begin{array}{l}\text { Self-assembled peptide gel with binding affinity to BMP-2 allowed prolonged retention of the GF and } \\
\text { promoted superior spinal fusion rates in vivo (rat posterolateral lumbar intertransverse spinal fusion } \\
\text { model) relative to controls and reduced the required BMP-2 dose by } 10 \text {-fold. } \\
\text { BMP-2 binding peptides were attached to dendrimers, covalently grafted to HA, for controlling the } \\
\text { release of BMP-2 from hydrogels. The binding peptides attenuated the release of BMP-2. }\end{array}$ & {$[77,81,82]$} \\
\hline TGF- $\beta 1$ & $\begin{array}{l}\text { HSNGLPL } \\
\text { Derived from phage display } \\
\left(K_{D}: \text { not determined }\right)\end{array}$ & $\begin{array}{l}\text { Self-assembled peptide gel containing a binding epitope to TGF- } \beta 1 \text { allowed localization of the GF, } \\
\text { prolonged its release and enhanced cartilage regeneration in vivo (full thickness chondral defect in } \\
\text { rabbit model). } \\
\text { TGF- } \beta 1 \text { binding peptides were attached to dendrimers, covalently grafted to HA, for controlling the } \\
\text { release of TGF- } \beta 1 \text { from hydrogels. The binding peptides attenuated the release of TGF- } \beta 1 \text {. }\end{array}$ & {$[75,81,82]$} \\
\hline $\begin{array}{l}\text { FGF-2 } \\
\text { TGF- } \beta 1\end{array}$ & $\begin{array}{l}\text { PAP }_{4} I_{S G_{3}} \text { YRARPAK } \\
\text { Derived from fibrinogen fragment } \\
\text { (Fg } \beta 31-47 \text { ) critical for GF binding } \\
\text { (TGF- } \beta 1: K_{D}=56.6 \text { nM; FGF- } 2 \text { : } \\
\mathrm{K}_{\mathrm{D}}=53.0 \mathrm{nM} \text {, estimated by SPR } \\
\text { for Fg } \beta 15-66 \text { ) }\end{array}$ & $\begin{array}{l}\text { Incorporation of Fg } \beta 15-66 \text { into a fibrin-mimetic (PEG functionalized with integrin-binding and } \\
\text { protease cleavable sequences) matrix as GF-binding domain. In vivo delivery of FGF-2 and PIGF- } 2 \text { in a } \\
\text { diabetic mouse model of impaired wound healing using the fibrin-mimetic matrix led to faster wound } \\
\text { closure and increased development of granulation tissue. }\end{array}$ & {$[73,83]$} \\
\hline
\end{tabular}

HA - hyaluronan; PEG - poly(ethylene glycol); $\mathrm{K}_{\mathrm{D}}$ : dissociation constant; PIGF-2 - placenta growth factor-2.

camptothecin, CPT) with a small $\beta$-sheet forming peptide sequence (VQIVYK) derived from the Tau protein, conjugated through a linker. These amphiphilic molecules self-assemble into discrete filamentous nanostructures (nanofibres or nanotubes) that can act as selfdelivering drugs, i.e., without the need for additional carriers, allowing the precise control of drug content by attaching one or more drug molecules. These DAs also allow high drug loading contents (23-41\%). Since most of the anticancer drugs need to be internalized by cells to exert their cytotoxic effect, a reducible linker (disulfylbutyrate, a molecule that breaks down in the presence of glutathione a reducing agent present in the cytosol) has been incorporated between the hydrophobic drug and the peptide segment, to allow intracellular drug release. Assuming that the hydrophobic drug and the linker are buried in the core of the filamentous nanostructures, the supramolecular morphology of DAs provides protection from the external environment and a mechanism for drug controlled release. In vitro toxicity experiments with different cancer cell lines have revealed identical toxicity of the synthesized DAs compared to free drug.

\subsubsection{Engineering release patterns}

Sequential release of multiple signals can be only achieved via strategies that allow precise and differential release kinetics for individual factors. There are many potential advantages of using self-assembled peptide carriers as delivery systems. Using rational molecular design (as described in Section 4.1.1), the release (diffusion kinetics) may be initiated and controlled by structural transitions (shape and size) induced by microenvironmental conditions, such as temperature, $\mathrm{pH}$, dilution, reduction agents or enzyme activities.

4.1.2.1. Dilution-, temperature- and $\mathrm{pH}$-mediated release. Peptides can adopt different conformations and change their structure in response to changes in concentration, $\mathrm{pH}$ or temperature. For example, cationic dipeptides $\left(\mathrm{NH}_{3}^{+}\right.$-FF-CONH$\left.{ }_{2} \cdot \mathrm{HCl}\right)$ have been used to fabricate nanotubes to bind negatively charged nucleic acids [50]. These cationic dipeptides self-assemble into nanotubes at physiological $\mathrm{pH}$ through $\pi-\pi$ stacking and hydrogen bonding, but upon dilution they rearrange to form vesicles, probably as a result of electrostatic repulsion. Immobilization of DNA has been achieved through electrostatic interactions and this binding does not disturb the tubular nanostructure. Intracellular delivery of DNA has been demonstrated with HeLa cells, mostly likely after conversion into vesicles.

The trifluoracetate (TFA) salt of a peptide amphiphile $\left(\mathrm{C}_{15} \mathrm{H}_{31} \mathrm{CONH}-\right.$ KTTKS- $\left.\mathrm{CO}_{2} \mathrm{H}\right)$ can assemble into nanotapes $\left(20^{\circ} \mathrm{C}\right)$ that at higher temperature rearrange into micelles [54]. This transition can be used to control the amount of molecules encapsulated within these nanostructures and also their release by a temperature change.

Golderberger and collaborators [55] have designed self-assembling peptide amphiphiles (PAs) capable of undergoing morphological transitions within very narrow $\mathrm{pH}$ changes (tenths of a $\mathrm{pH}$ unit) existing either as single molecules or spherical micelles under normal physiological conditions ( $\mathrm{pH} 7.4$, in serum-like ionic conditions) or as nanofibres in acidic environment ( $\mathrm{pH}$ 6.6). They have developed a PA design strategy consisting of a ratio of one hydrophobic amino acid (I, F, V, Y) to four glutamic acids (E) $\left(\mathrm{C}_{15} \mathrm{H}_{31} \mathrm{CONH}-\mathrm{IA}_{3} \mathrm{E}_{4}-\mathrm{CONH}_{2}, \mathrm{C}_{15} \mathrm{H}_{31} \mathrm{CONH}-\mathrm{FA}_{3} \mathrm{E}_{4}-\right.$ $\mathrm{CONH}_{2}, \mathrm{C}_{15} \mathrm{H}_{31} \mathrm{CONH}-\mathrm{VA}_{3} \mathrm{E}_{4}-\mathrm{CONH}_{2}, \mathrm{C}_{15} \mathrm{H}_{31} \mathrm{CONH}-\mathrm{YA}_{3} \mathrm{E}_{4}-\mathrm{CONH}_{2}$ ) and this ratio has been essential to enable the morphological transition in a desired $\mathrm{pH}$ range (6.0-6.6). This transition is concentrationdependent and by varying the amino acids in the $\beta$-sheet-forming region $\left(\mathbf{X A}_{3}\right)$, the transition $\mathrm{pH}$ could be systematically tuned (propensity for $\beta$-sheet formation: $\mathrm{I}>\mathrm{F}>\mathrm{V}>\mathrm{Y}$ ). They have further incorporated a magnetic resonance imaging agent $(\mathrm{Gd}(\mathrm{DO} 3 \mathrm{~A}))$ at the PA C-terminus and the molecule-to-nanofibre transition is still observed, although the $\mathrm{pH}$ transition is shifted to $\mathrm{pH}$ 5.7. Similarly, peptide sequences with the ability to bind GFs (Table 2) could be incorporated at the PA C-terminus to capture and retain a specific GF at the surface of the PA assemblies. This study demonstrates that slight changes in $\mathrm{pH}$ can induce morphological transitions on self-assembled PAs molecularly designed for precise $\mathrm{pH}$ tuning and this provides the possibility to control the release of bioactive molecules bound to these PAs.

4.1.2.2. Enzyme-mediated release. Matrix metalloproteinases (MMPs) are often overexpressed during tissue remodelling and in certain pathologies (e.g. inflammation, cancer) and can cleave a variety of ECM proteins. Because MMPs recognize specific amino acid sequences, this property has been explored to design MMP-sensitive delivery systems. Variations of the sequence GPX $\mathbf{G} \downarrow \mathbf{L X} \mathbf{X}_{2} \mathbf{G}$ (where $\downarrow$ denotes the expected cleavage site, $X_{1}$ being preferentially alanine or leucine, $X_{2}$ being preferentially glycine), known to be sensitive to gelatinases (MMP-2/MMP-9) cleavage, have been incorporated into self-assembling peptide-based carriers for inducing structural transitions upon MMP-2/MMP-9 cleavage and mediating the release of anticancer drugs [47].

Ulijn and collaborators [56] have recently developed a MMP-9 triggered micelle to fibre transitions for controlled release of doxorubicin (anticancer drug). The peptide design consists of phenylacetylFFAGLDD- $\mathrm{CO}_{2} \mathrm{H}$. The PhAc-FFA is the fibre-forming segment and provides a hydrophobic environment for drug entrapment. The dipeptide GL is the MMP-9 cleavable sequence, while DD imparts a hydrophilic character to the peptide favouring micelle formation. Upon cleavage by MMP-9, the hydrophilic shell is removed from the initial peptide 
segment with consequent conversion into fibres due to predominant hydrophobic forces. Thus, morphological transition allows the entrapment of hydrophobic drugs and a mean for their sustained release.

The release of liposome contents mediated by MMP-9 has been proposed by Sarkar et al. [57]. They have incorporated collagenmimetic peptides containing a MMP-9 substrate $\left(\mathrm{H}_{2} \mathrm{~N}-\mathrm{GPQGLAGQRG}\right.$ IVGLOG- $\mathrm{CO}_{2} \mathrm{H}, \mathrm{H}_{2} \mathrm{~N}$-GPQGIAGQR(GPO) ${ }_{4} \mathrm{GG}-\mathrm{CO}_{2} \mathrm{H}, \mathrm{H}_{2} \mathrm{~N}$-GPQGLAGQR (GPP) ${ }_{4} \mathrm{GG}-\mathrm{CO}_{2} \mathrm{H}, \mathrm{H}_{2} \mathrm{~N}-\mathrm{GPQGLAGQR}(\mathrm{GPO})_{4} \mathrm{GG}-\mathrm{CO}_{2} \mathrm{H}, \mathrm{H}_{2} \mathrm{~N}-\mathrm{G}(\mathrm{GPO})_{4}$ GLAGQR(GPO) $\left.{ }_{4} \mathrm{GG}-\mathrm{CO}_{2} \mathrm{H}\right)$ into the liposomes so the triple helical peptides are protruding from the surface of the liposomes for facile cleavage. The release of a dye from the liposomes occurs only in presence of MMP-9 and not by other proteolytic enzymes, demonstrating the specificity of the system. "Uncorking" of the liposomes by MMP-9 results in their content release. This system can be made sensitive to enzymes secreted during bone regeneration (e.g. alkaline phosphatase expressed by osteoblasts); the release of the GFs encapsulated within these liposomes can be triggered by these specific enzymes from the surrounding environment.

In a different approach, Cui and collaborators explore the activity of MMP-2 to degrade peptide cross-linkers $\left(\mathrm{CH}_{3} \mathrm{CONH}-\mathrm{K}_{2}\right.$ YGPQGIAGQ $\mathrm{YK}_{2}-\mathrm{CONH}_{2}, \mathrm{CH}_{3} \mathrm{CONH}-\mathrm{K}_{2}$ YIPVSLRSGYK $_{2}-\mathrm{CONH}_{2}$ ) containing two substrates to MMP-2 (GPQG $\downarrow$ IAGQ and IPVS $\downarrow$ LRSG), that stabilize supramolecular peptide filaments [58]. Hydrogels of the cross-linked filaments can be potentially used as carriers for protein delivery, whose release would occur through the dissociation of peptide filaments upon degradation of the peptide cross-linkers by MMP-2.

Other enzymes have also been used to trigger the release of drugs from self-assembled peptide carriers. For example, Stupp and coworkers have designed a peptide amphiphile $\left(\mathrm{H}_{2} \mathrm{~N}-\mathrm{KRRASVAGK}\left[\mathrm{C}_{12}\right]-\right.$ $\mathrm{NH}_{2}$ ) containing a consensus sequence (RRXSY, where $\mathrm{X}$ is any residue and $Y$ is a hydrophobic residue) that is the substrate of a protein kinase A (PKA) [59]. Upon treatment with PKA, the PA becomes phosphorylated (phosphorylation of serine ( $\mathrm{S}$ ) residue) causing the disassembly of the original self-assembled cylindrical structures. Subsequent treatment with alkaline phosphatase enzyme, which cleaves the phosphate groups, results in PA reassembly. Disassembly in the presence of PKA allows the enzyme-triggered release of an encapsulated cancer drug.

The protease $\alpha$-chymotrypsin has also been used to cleave the PA $\mathrm{C}_{15} \mathrm{H}_{31} \mathrm{CONH}-\mathrm{KKFFVLK}$ [60]. Two cleavage sites within the PA are identified. The first preferential cleavage site is between the two $\mathrm{F}$ residues and leads to a higher abundance of both $\mathrm{C}_{15} \mathrm{H}_{31} \mathrm{CONH}-\mathrm{KKF}$ and FVLK. The second cleavage process occurs at the $\mathrm{C}$ terminus of the second $\mathrm{F}$ residue to produce $\mathrm{C}_{15} \mathrm{H}_{31} \mathrm{CONH}-\mathrm{KKFF}$ and VLK. While the $\mathrm{C}_{16}$-KKFFVLK PA forms nanotubes, the $\mathrm{C}_{15} \mathrm{H}_{31} \mathrm{CONH}-\mathrm{KKF}$ and $\mathrm{C}_{16}$-KKFF PAs both self-assemble into spherical micelles. The change in nanostructure from $\mathrm{C}_{15} \mathrm{H}_{31} \mathrm{CONH}-$ KKFFVLK to $\mathrm{C}_{15} \mathrm{H}_{31} \mathrm{CONH}-\mathrm{KKF}$ and $\mathrm{C}_{15} \mathrm{H}_{31} \mathrm{CONH}$-KKFF leads to macroscopic changes in sample appearance and this transition can be useful for the delivery of bioactive molecules.

4.2. Self-assembly and peptide functionalization approaches to control retention and presentation of GFs

The covalent immobilization of proteins into self-assembling nanomaterials allows insertion of precise combinations of proteins into supramolecular systems, as it has been reported recently by Collier and co-workers [61]. They have proposed a multicomponent system, made of self-assembling peptides and fusion proteins having a $\beta$-sheet fibrillizing domain, that upon mixing co-assemble into polypeptide nanofibres displaying precise combinations of protein ligands (Fig. 3A). The strategy has allowed the integration of proteins with different biophysical properties (fluorescent proteins, cutinase enzyme) into $\beta$ sheet peptide nanofibres and retention of their activity. Although this strategy has not been used for the immobilization of GFs, the versatility of the proposed approach may offer great potential for the presentation and delivery of multiple GFs. In a different approach, Mercado et al. [62] have reported the immobilization of BMP-2 on self-assembled nanoparticles (NPs). rhBMP-2 has been grafted to self-assembled poly(lactide fumarate) (PLAF) or poly (lactide-co-glycolide fumarate) (PLGF) and poly(lactide-co-ethylene oxide fumarate) (PLEOF) NPs to investigate its release from the NPs and subsequent osteogenic activity on bone marrow stromal cells. The PLAF and PLGF macromers have been functionalized with $\mathrm{N}, \mathrm{N}^{\prime}$-disuccinimidyl carbonate to obtain succinimide-terminated macromers (PLAF-NHS, PLGF-NHS). After NP self-assembly, rhBMP-2 has been attached to the NPs by reaction between the protein amino groups with succinimide groups in the NPs. PLAF and PLGF are biodegradable polymers and the release of rhBMP-2 has been dominated by degradation/erosion of the NPs, resulting in a linear release in the first 5 and 15 days, depending on NP formulation (PLGF-NHS or PLAF-NHS, respectively). Furthermore, the system has been able to preserve the protein conformation after release and induce differentiation of osteoprogenitor cells. The proposed system can thus provide localized and sustained delivery of BMP-2 at the bone regeneration site.

Covalent immobilization of GFs enables a stable linkage, but requires chemical coupling of the GF to the carrier material, which may interfere with its activity. In addition, if cell signalling requires GF in its free form, a mechanism for the GF release needs to be further implemented (e.g. degradable/sensitive linker).

An alternative strategy for the non-covalent immobilization of proteins on supramolecular assemblies has been proposed by Matsumura et al. [63]. They have constructed biotinylated peptides consisting of three parts: biotin, a linker and a $\beta$-sheet forming region (PKFKIIEFEP) (Fig. 3B). They have shown that peptide nanotubes, resulting from the self-assembly, could be decorated with proteins using the binding of anti-biotin antibody to biotin groups displayed on the peptide tubes. Similarly, different proteins could be immobilized on the surface of these biotinylated nanotubes through streptavidin-conjugated proteins. Using a similar approach, Miller et al. [64] have investigated the delivery of IGF- 1 and TGF- $\beta 1$ adsorbed or tethered to self-assembled peptide $\left((\mathrm{KLDL})_{3}\right)$ nanofibres to stimulate the proteoglycan production by chondrocytes. Tethering is achieved through biotin-streptavidin bonds using biotinylated- $\mathrm{CH}_{3} \mathrm{CONH}-(\mathrm{KLDL})_{3}-\mathrm{CONH}_{2}$ and biotinylatedIGF-1 complexed with streptavidin. This system has initially been proposed for the local delivery of IGF-1 as therapy for myocardial infarction [65] since it has been shown that this strategy does not prevent the selfassembly of RAD16-II peptide $\left(\mathrm{CH}_{3} \mathrm{CONH}\right.$-RARADADARARADADA$\mathrm{CONH}_{2}$ ) into nanofibres. Tethering GFs to the peptide nanofibres has resulted in increased retention and long-term delivery, but it does not achieve the same bioactivity as soluble delivery, which indicates the importance of protein presentation when designing delivery strategies. Sustained delivery of platelet-derived growth factor (PDGF-BB) inside the myocardium of rats has also been achieved using a self-assembled RAD16-II peptide gel system [66]. Although these peptide nanofibres do not have any specific binding sequence for PDGF-BB, it has been postulated that their amphiphilic nature may provide binding through weak molecular interactions.

As previously mentioned, different ECM components can bind GFs and serve as a reservoir, while regulating their activation, synthesis, and degradation [67]. Understanding these interactions is critical to modulate GF activity in different ways and to rationally design carrier systems for the spatiotemporal control of GF release and ensuring proper cell regulation. Binding GFs with strong affinity can alter their local concentration, limit their mobility (retain activity while bound) and inhibit their uptake by surrounding cells.

Based on their ability to bind sulfated GAGs, various GFs (VEGF, FGF2, BMP-2) have been immobilized in different self-assembling delivery carriers through the incorporation of heparin, heparin-like molecules [68] or heparin-binding peptides [69-72]. The ability of non-proteoglycan ECM proteins, like fibronectin (FN) and fibrin(ogen) (Fg) to bind GFs has also been explored for GF delivery [73]. Hubbell's group has demonstrated that certain FN (FN III12-14, consisting of 284 amino acids and also known as the FN heparin-binding domain II) and 
A

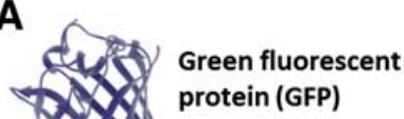

protein (GFP)

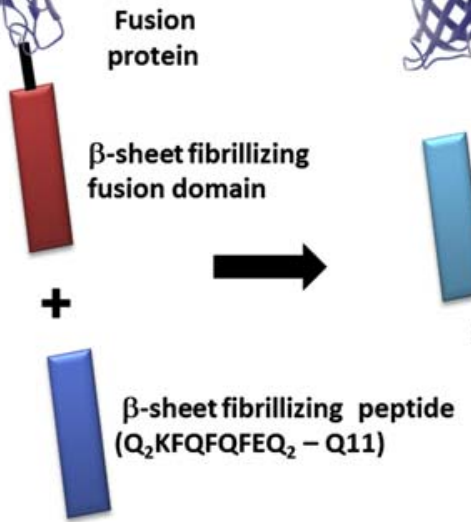

B

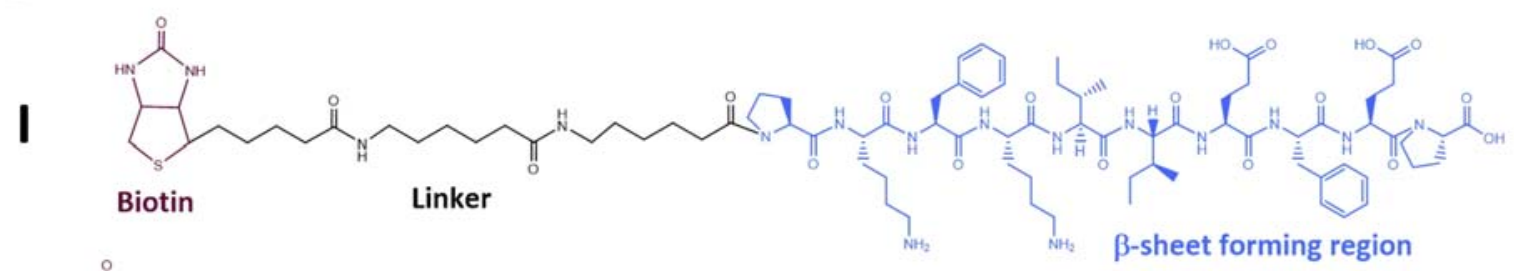

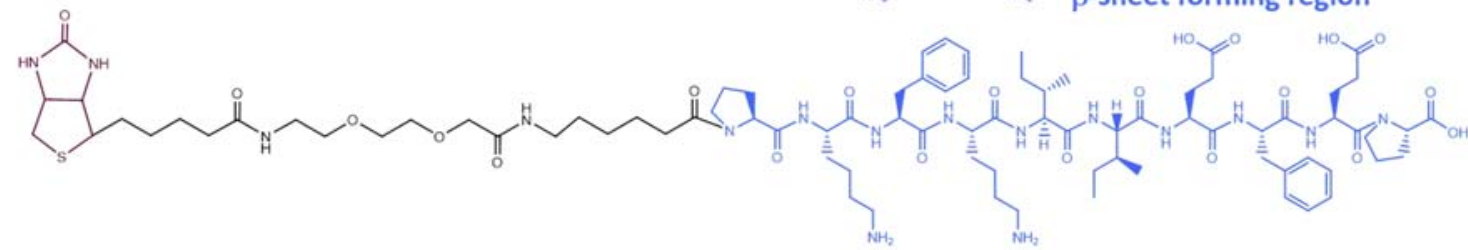

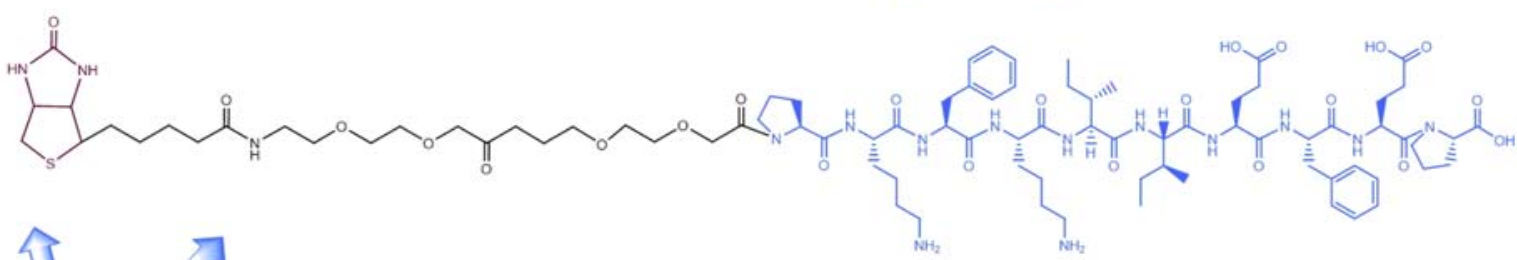

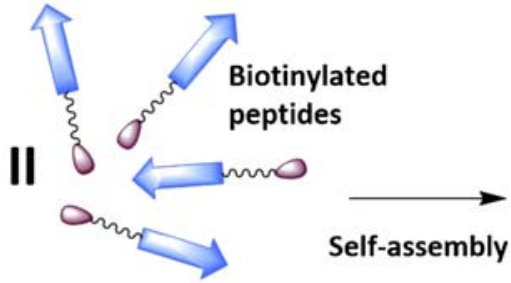
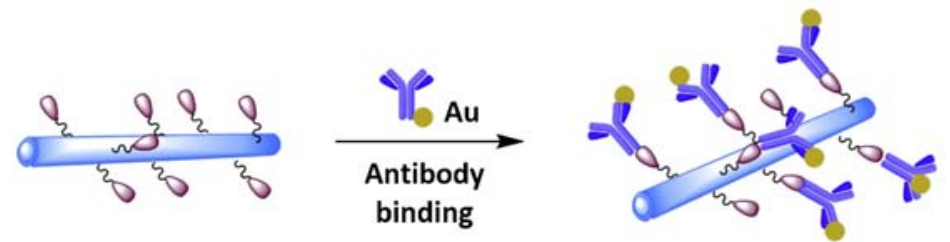

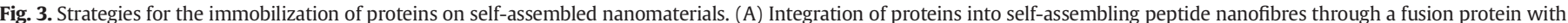

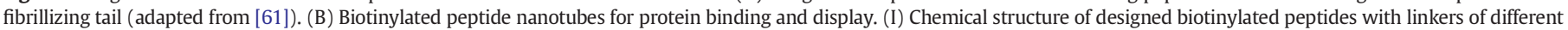
hydrophobicity. (II) Self-assembly of biotinylated peptides into nanotubes and modification with anti-biotin antibodies labelled with gold nanoparticles (adapted from [63]).

Fg (Fg B1-66, 66 amino acids) fragments promiscuously bind to GFs from different families (PDGF, FGF, VEGF, TGF- $\beta$, BMP). They have further used these fragments to functionalize synthetic hydrogels for GF presentation and promoting tissue repair in vivo. This strategy has been shown to promote wound and bone tissue healing [73]. An interesting possibility to explore would be to use specific regions of these fragments, known to be critical for GF binding (shorter sequences, Table 2) so they could be easily incorporated into self-assembling carriers. Simpler delivery systems may improve safety and costeffectiveness, and facilitate translation into the clinic.
While co-delivery of several GFs is most likely required to build an efficient and proper regenerative environment, that fully control the different phases of healing [8], the delivery of specific GFs at a predetermined time may require more selective binding strategies. A possible strategy consists in using phage display to identify peptide sequences that bind specifically and selectively to GFs (Table 2). Peptides with affinities to a wide range of targets, including GFs, can be accessed through the MimoDB database (freely available at http://immunet.cn/ mimodb [74]). Using a phage-derived peptide sequence with binding affinity to TGF- $\beta 1$ (Table 2), Shah et al. [75] have designed a 
supramolecular system consisting of self-assembled peptide nanofibres displaying an epitope for TGF- $\beta 1\left(\mathrm{H}_{2} \mathrm{~N}-\mathrm{HSNGLPLG} \mathrm{SE}_{3} \mathrm{~A}_{3} \mathrm{~V}_{3}(\mathrm{~K})-\left[\mathrm{C}_{12}\right]-\right.$ $\mathrm{NH}_{2}$, Fig. 4A-II). Peptide amphiphiles (PAs) are a class of molecules in which a hydrophobic alkyl tail (Fig. 4A-I and II, black) is covalently bound to a peptide segment that includes two or three distinct domains. The sequence close to the alkyl tail is designed to have strong propensity to form intermolecular hydrogen bonding and originate $\beta$-sheets (Fig. 4A-I and II, green). A second domain contains charged amino acids (Fig. 4A-I-and II, red) for enhanced solubility in water and allowing electrostatic screening. The third domain (Fig. 4A-II, blue) is typically used for displaying bioactive signals at the nanofibre surface, as these molecules are known to self-assemble into high-aspect-ratio cylindrical nanostructures. To allow flexibility and extended presentation of the bioactive signal, a linker region (Fig. 4A-II, grey) is included before the epitope domain. When mixed with TGF- $\beta 1$, the supramolecular system, in the form of self-assembled peptide gel, has been able to retain and slow-down its release. The incorporation of TGF- $\beta 1$ into these peptide gels has also promoted the chondrogenic differentiation of encapsulated stem cells, possibly to the interaction of TGF- $\beta 1$ and its receptors (Fig. 4B), and the regeneration of articular cartilage in vivo (Table 2 ).

Using the same approach, the Stupp group has recently designed a PA nanofibre system with binding affinity to BMP-2 $\left(\mathrm{H}_{2} \mathrm{~N}\right.$ TSPHVPYG ${ }_{3} \mathrm{SE}_{3} \mathrm{~A}_{3} \mathrm{~V}_{3}(\mathrm{~K})\left[\mathrm{C}_{12}\right]-\mathrm{NH}_{2}$, Table 2) to create a self-assembled gel for inducing osteogenesis in spinal fusion and to reduce the amount of BMP-2 used clinically in these procedure [77]. When in solution, the PA nanofibres have induced the differentiation of $\mathrm{C} 2 \mathrm{C} 12$ pre-myoblast cells into osteoblasts through BMP-2 bound to the PA nanofibres. In vivo studies, using the BMP-2-binding nanofibres in a translational model of bone regeneration (Table 2), have shown that this system allowed a 10-fold reduction in the BMP-2 dose to achieve 100\% fusion rate. This observed efficacy has been explained by the ability of this BMP-2-binding peptide nanofibres to both capture exogenously delivered or endogenously expressed GF.

Immobilization of GFs by non-covalent interactions also offers the possibility to better control their retention, distribution and release, by tuning the molecular interactions (strong, moderate, weak). In this context, a valuable tool consists in determining the association $\left(\mathrm{K}_{\mathrm{a}}\right)$ and dissociation $\left(\mathrm{K}_{\mathrm{D}}\right)$ constants between the GFs and specific functionalities in the carrier system. Surface plasmon resonance (SPR), isothermal titration calorimety (ITC) and quartz crystal microbalance (QCM) have been widely used to study macromolecular interactions. Delivery systems based on reversible affinity mechanisms are an effective alternative to control the availability of GFs without the need of chemical modification of the protein. Table 2 lists peptide sequences with binding affinity to GFs with relevance in bone regeneration. Through molecular design, affinity and release of GFs can be engineered to regulate cell signalling.

\subsection{Polyelectrolyte complexation approaches to design GAG-based carriers}

Interpolyelectrolyte complexation (IPEC, Fig. 5) is the easiest encapsulation method for delivery of charged biomacromolecules because simple mixing with a carrier bearing opposite charge leads to selfassembly. The simplicity of the method, together with the predictability of the generated structures and the possibility to perform the complexation in aqueous solutions at or near physiological $\mathrm{pH}$ and ionic strength, make this method a preferable approach for delivery of sensitive therapeutics such as proteins.

In fact, the feasibility of polysaccharide-based IPECs has been already demonstrated in the field of bioengineering as this is the most common method for gene delivery: the phosphate groups of RNA and DNA

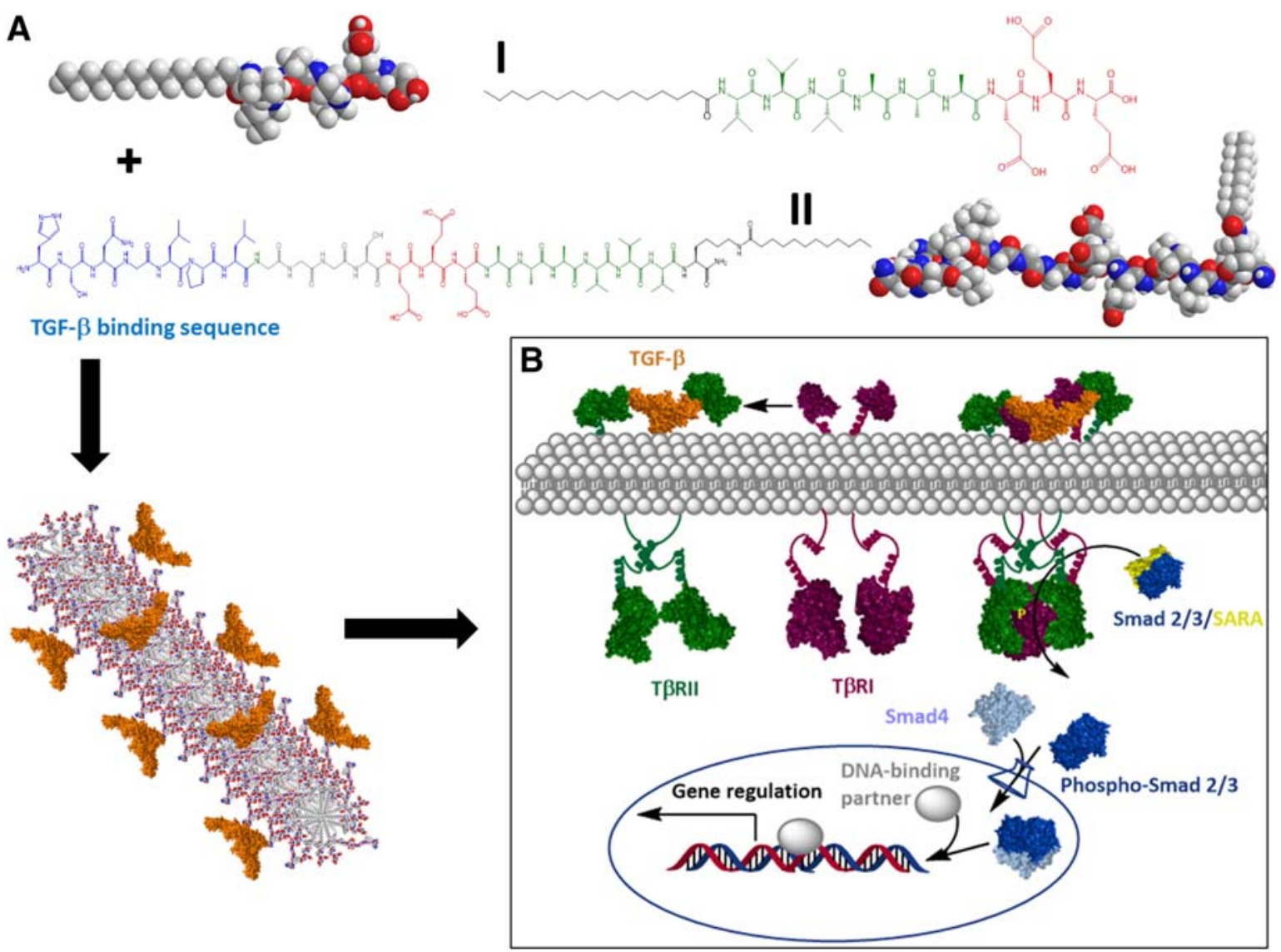

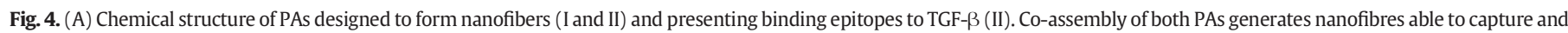
display the GF for signalling (adapted from [75]). (B) Schematic depiction of TGF- $\beta$ signalling (adapted from [76]). 

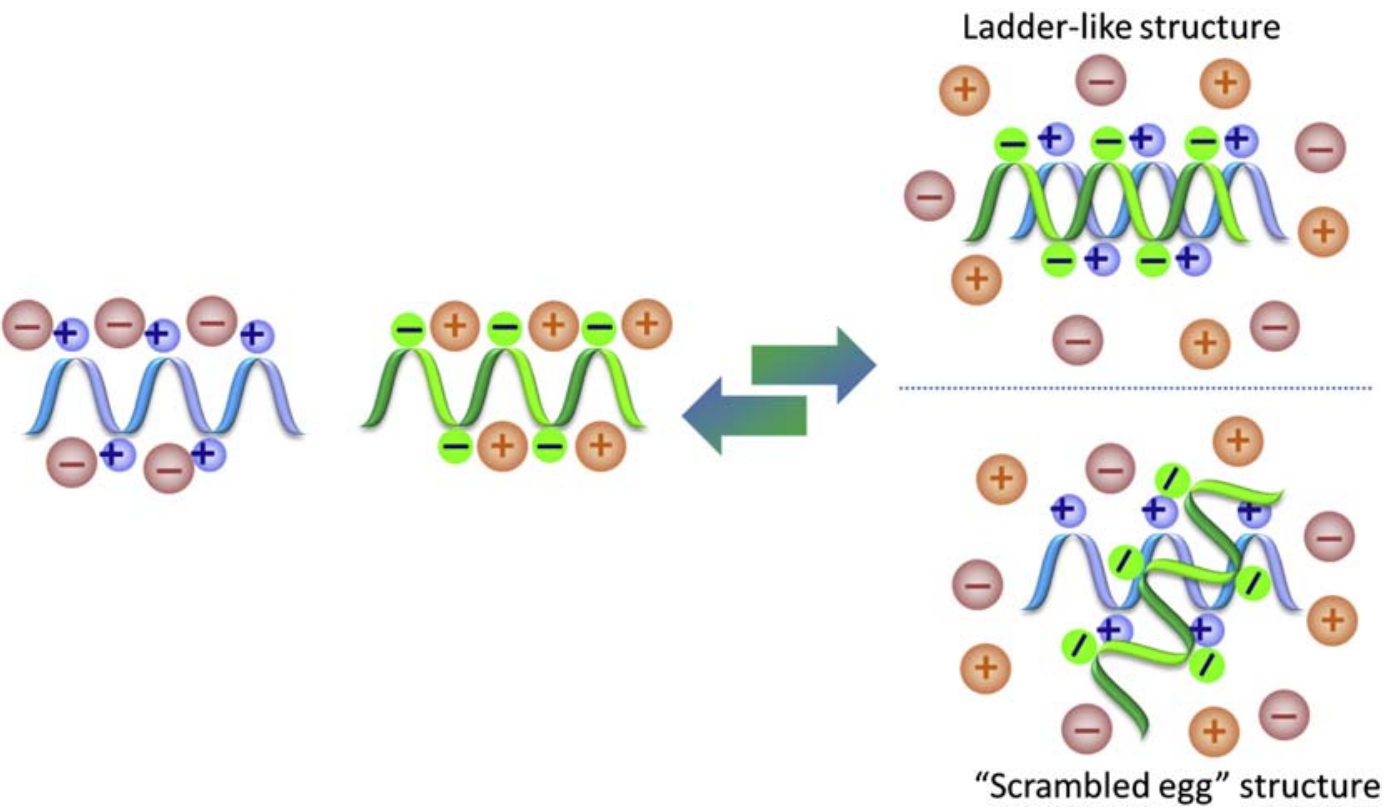

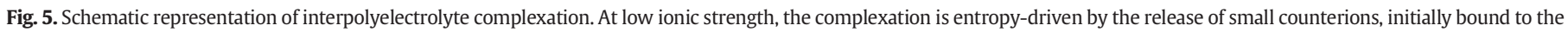
polyelectrolytes. The polyions assemble into highly ordered (ladder-like) or disordered (scramble egg) structures.

(strong negative charge) readily interact with polyamines, such as chitosan, leading to the formation of complexes (so-called polyplexes) that are stable under physiological conditions [84]. Proteins, however, differ from the nucleotides by their lower charge density. The current approaches targeting stabilization of protein IPECs can be divided in two main groups: (i) IPEC that involve the use of additional polycation (most of the GFs in Table 1 have basic pI and thus in IPEC they are acting as polycations) usually chitosan and (ii) IPEC involving polyanions that have been additionally functionalized (most often sulfated) in order to present higher negative charge. In any of these approaches, the conditions for the formation of stable complexes must be optimized. Several parameters, such as mixing regime, medium conditions and macromolecular characteristics of the polyelectrolytes are decisive for the formation, morphology and stability of the complexes, as IPEC is a very fast (less than $5 \mu$ s [85]), mainly kinetically driven process.

\subsubsection{Mixing regime}

The first step in the preparation of polyelectrolyte complexes (PECs) is the determination of the stoichiometry of the ionic binding, i.e. the charge ratio between the polyions that will lead to shift in the equilibrium (Fig. 5). There are several techniques that can be used for this purpose, among which turbidity $[86,87]$ and the electrophoretic light scattering [88-90] are the most common ones. Using these two techniques, and quite dilute water solutions of polyelectrolytes (below $1 \times 10^{-3} \mathrm{~g} / \mathrm{mL}$ ) it has been demonstrated that stable complexes are formed in an excess of one of the polyions. The obtained complexes comprise a neutral core surrounded by stabilizing charged shell that is built from the excess component $[86,88]$ (Fig. 6). This behaviour has been observed for heparin that is a strong polyanion, but also for HA which is a typical weak polyanion [88]. Different cellular compartments can be targeted by selecting the mixing ratio between the polyions: when the polycation is in an excess, an overall positive charge of the complex is expected and thus, cytoplasm and mitochondria will be the targeted compartment. Lysosomes are targeted by anionic nanoparticles, i.e. in the case of an excess of the polyanion [91].

The GF can be incorporated in the PEC during the assembly process (usually as a polycation that is in deficit) $[89,90,92]$ or after the PEC has been already formed by its incorporation in the charged stabilizing shell [93] (Fig. 6). The former approach offers superior control over the encapsulation efficiency and better protection of the GF against environmental stress conditions. The stabilizing shell is not formed when a stoichiometric charge ratio is used (1:1). In this case, the obtained complexes are hydrophobic because of the mutual screening of the charges and as a result secondary aggregation/flocculation occurs [86]. Schatz et al. have demonstrated that this flocculation is irreversible when polysaccharides are used as polyions (Table 3), i.e. it cannot be avoided by following addition of large excess of one of the polyions, most probably because of the strong electrostatic interactions ( $\Delta \mathrm{pKa} \sim 4.5$ ) already established between the polyions, but also as a result of the numerous H-bonding occurring between the polysaccharides (chitosan as a polycation and GAGs as polyanions). The rate of the polyelectrolytes mixing does not influence significantly the assembly process: one-shot additions of polyelectrolytes or slow dropwise supplement result in complexes with the same properties [86]. In fact, this is an expected result, since the IPEC is a fast, kinetically-driven process.

\subsubsection{Macromolecular characteristics of the polyelectrolytes}

Molecular weight, charge density and chain stiffness of the polyelectrolytes are the main properties that can influence the assembly process. It has been demonstrated that the molecular weight determines the size of the formed complex for polysaccharides [99]. Because polysaccharides have relatively stiff conformations, one can assume that the use of polysaccharides with high molecular weight will result in the formation of a more swollen core and thus, in larger assemblies. However, this behaviour is not always observed. For example, Huang et al. have studied several polycations with similar molecular weights in combination with dextran sulfate for VEGF delivery [90]. They have found that the size of the formed complexes is dependent of the charge density of the polycations and the diameter of the formed complexes decreased in the following order: chitosan $(284 \pm 4)>$ polyethyleneimine $(258 \pm 14)>$ poly-L-lysine $(159 \pm 3)$. These PECs have shown different encapsulation efficiency but in all cases a stabilization effect of dextran sulfate over VEGF secondary structure has been observed. This effective stabilization has resulted in an increased proliferation of human umbilical vein endothelial cells when compared with the negligible effect of the free supplemented GF. Charge density is also important for the stability (assembly/disassembly equilibrium) of the PEC. Recent studies with different GAGs have demonstrated that HA and poly-L-lysine (PLL) do not form PECs that are stable at physiological 

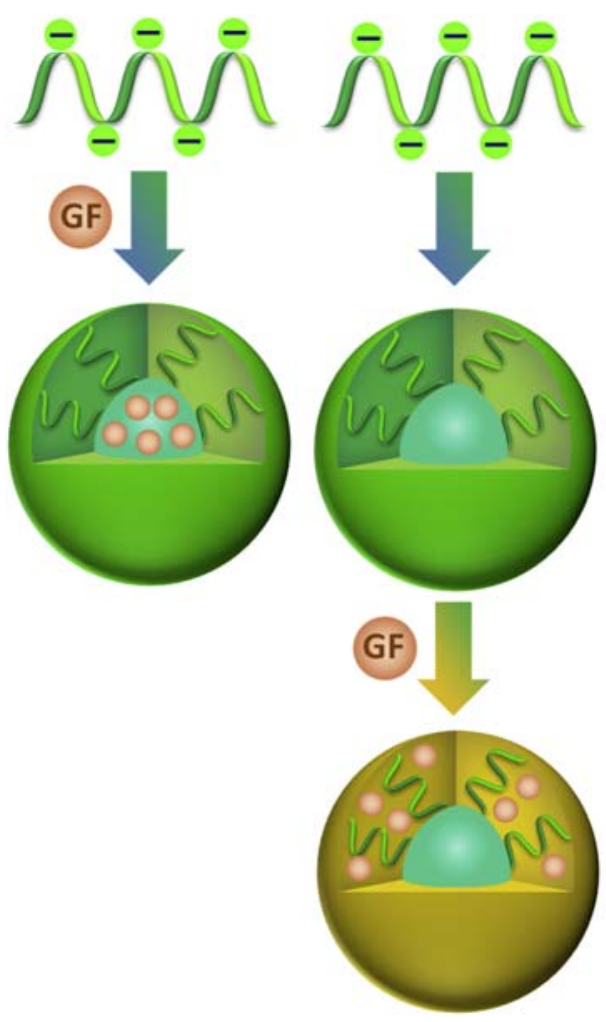

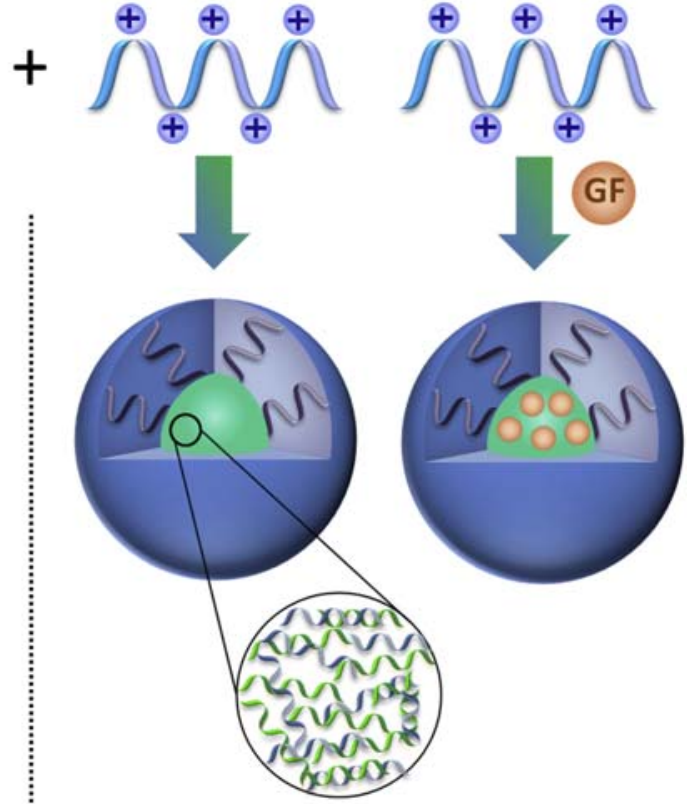

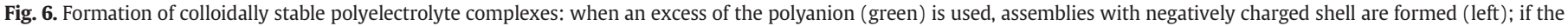
polycation (blue) is in excess, the shell is with positive charge (right). GFs can be incorporated during the assembling or after the complex has been formed.

ionic strength $[89,100]$. If sulfated GAGs are used instead (higher negative charge) the stability of these complexes is significantly improved [89].

\subsubsection{Medium conditions}

Interpolyelectrolyte complexes are responsive systems sensitive to changes in their environment. The stability of the complexes in water or in culture media (abundant of other proteins and salts) is quite different. The presence of small amount of sodium chloride $(\mathrm{NaCl})$ alone can lead to dramatic changes in the aggregation and stability of the complexes. Upon addition of small amount of salt, an initial swelling is typically observed for complexes that have been formed by weak polyelectrolytes in pure water. This swelling state facilitates polyions exchange and substitution reactions in media with higher ionic strength and/or presence of components with high molecular weight or higher charge density. Increasing quantity of salt can lead to complex disruption at so called critical salt concentration. This concentration is characteristic for each PEC and depends on the charge densities of polyions, as already discussed above.

\subsubsection{Release of the encapsulated GFs}

Carriers providing a controllable release profile that meets the temporal and spatial demands of regenerating tissue are of upmost importance in the design of GF delivery systems. So far, several different strategies for tailoring the release characteristics of PEC have been reported. Chen et al. have demonstrated that by adjusting the mixing ratio between dextran sulfate and chitosan, the release rate of the encapsulated biomolecule can be controlled [101]. Lee et al. have developed dual-loaded heparin-based micelles by using different encapsulation methods for each of the bioactive agents (Fig. 6). While indomethacin was loaded into the core of the complex, the FGF-2 was incorporated into its outer shell [102]. Contrary to what would be expected (faster release of FGF-2 against indomethacin), more sustained release of the GF is observed. The authors explained this unexpected behaviour by the favourable ionic binding of FGF-2 to heparin, as compared with the hydrophobic interactions that keep the indomethacin in the inner core of the complex. Selecting polyions with proper macromolecular characteristics can also be used to tailor the release profile via controlled degradation/disassembly of the PEC and physiological diffusivity. Zern et al. have shown that FGF-2 is released slower from heparin based PEC when an additional polycation with lower molecular weight is used (20\% release of the encapsulated GF for 1 month), while the PEC formed with high molecular weight polycations releases approximately $50 \%$ of incorporated GF over the same period of time [94]. Another possible release mechanism is related with the biodegradability of the used

Table 3

Examples of natural polysaccharides used as polyanions in the design of PECs nanoassemblies for delivery of GFs.

\begin{tabular}{|c|c|c|c|c|}
\hline GF (polycation) & Polysaccharide (polyanion) & Additional polycation & Observed effect & Ref \\
\hline FGF-2 & Heparin & poly(argininate glyceryl succinate) & Vascularisation & {$[94,95]$} \\
\hline FGF-2 & Heparin & Chitosan & Increased marrow stem cells proliferation & [96] \\
\hline FGF-2 & Chondroitin sulfate & Chitosan & Increased marrow stem cells proliferation & [96] \\
\hline FGF-10 & Dextran sulfate & Chitosan, PLL & Enhanced proliferation of ECs & [97] \\
\hline VEGF & Dextran sulfate & Chitosan, PLL & Increased HUVECs proliferation & [90] \\
\hline VEGF & Heparin & Chitosan & Increased extracellular matrix production and accelerated vascularization in vivo & [98] \\
\hline Platelet lysates & Chondroitin sulfate & Chitosan & Osteogenic differentiation of adipose derived stem cells & {$[93]$} \\
\hline
\end{tabular}

ECs - endothelial cells; HUVECs - human umbilical vein ECs; PLL - poly-L-lysine 
polyions [103]. GAGs can be degraded by enzymes that are overexpressed during diseased states (e.g. hyaluronidase is overexpressed in patients with rheumatoid arthritis) and thus they are an excellent example of responsive polyanions that can release the encapsulated bioactive agent under these conditions.

\subsubsection{Micellar delivery systems based on block co-polymers}

The physicochemical properties of GF carriers, their size and size distribution, as well as their surface charge, determine the in vivo fate of the delivered GF. The described above PECs need to be charged in order to confer them colloidal stability. However, a charged carrier is not always the best one in terms of delivery strategy, as it is very likely that it can interact non-specifically with proteins under physiological conditions before reaching the targeted site. Some years ago, Kataoka et al. has proposed the use of block copolymer micelles as delivery vehicles aiming to overcome this drawback [104]. The delivery systems based on block copolymers present several advantages over other polymeric release systems: sizes smaller than $200 \mathrm{~nm}$ (particles with larger size are easily uptaken from the reticuloendothelial system and rapid clearance from the circulation [105]), superior control over the nanostructure assembly and release profile, tissue penetrating ability, reduced toxicity among others [89]. They are assembled upon mixing of stoichiometric amounts of two polyelectrolytes, one (or both) of which is covalently attached to another hydrophilic non-ionic segment that itself does not participate in the complexation process (Fig. 7). As a result, the formed micellar structure comprises a PEC inner core that act as a molecular reservoir and a neutral (most often PEG) shell that confer colloidal stability to the nanocarrier and delay phagocytosis by prolonging the blood circulation time (stealth effect). These properties are of upmost importance in the case of GF delivery for bone regeneration, where a time-delay and stable controlled release with little initial burst is desirable, while the carrier manoeuvres the complex intricacies of bone structure to reach to the diseased site [106]. Moreover, the small size of the vehicles allows direct endocytosis and thus, the encapsulated protein can be released either outside or inside the targeted cell, allowing achievement of the desired effect by using smaller amounts of protein [91].

Such core-corona structures have been known for synthetic block copolymers for several years $[107,108]$ and have been applied for DNA delivery [109]. Recently, GAG-b-PEG copolymers have been described $[89,100,110]$ and it has been demonstrated that they can be used for encapsulation of FGF-2 [89]. The main challenge in this approach is to bind the GAG polyanion to the PEG without altering its bioactivity. Oxime click chemistry and binding via the reductive end of the GAG has been proposed as a feasible approach for this synthesis [110]. The first trial with HA-b-PEG and PLL has demonstrated that complexes are formed at low ionic strength, but when physiological value is reached the formed complexes disassemble [100]. In follow-up studies, block copolymers with larger negative charge have been used and as a result the stability of the complexes was improved [89]. Moreover, it has been demonstrated that the size of the formed complexes also depends on the charge of the ionic component in the copolymer: higher charge density resulted in smaller complexes.

The future challenge in the field involves the assembly of block copolymers with different non-ionic segments (Fig. 8). Such complexes have been already realized for synthetic polymers. Functionalization of the PEG free end with short targeting agent must lead to more efficient delivery strategies.

\section{Conclusions and outlook}

Learning from Nature is a constant challenge: processes and properties in Nature, which have been optimized over millions of years of evolution, are giving us inspiration to develop novel functional biodevices. In the fast developing field of targeted controlled delivery, scientists have made several crucial technological advances in the past few years that have facilitated to overcome at least some of the obstacles related to the design and further exploitation of responsive delivery systems. The power of supramolecular forces to develop dynamic selfassembling carriers, that are programmed to form compartments for therapeutics and change shape and size in response to subtle environmental switches, offers great potential to deliver bioactive proteins for tissue regeneration. A major promise of these carrier systems is their potential to be tuned in a way that reversible transitions can be made into their assembly state/morphology but also their affinity can be engineered. Although self-assembling carriers have shown great promise for the delivery of small drugs, larger molecules like GFs pose additional challenges. To fully exploit these systems in regenerative medicine applications, further efforts should be devoted to dissect the interactions that control GF binding and release, and identify the critical elements to construct simplified ECM surrogates. In addition, many of these self-assembled carriers remain as a proof-of-concept since their design and properties require further optimization. Application of

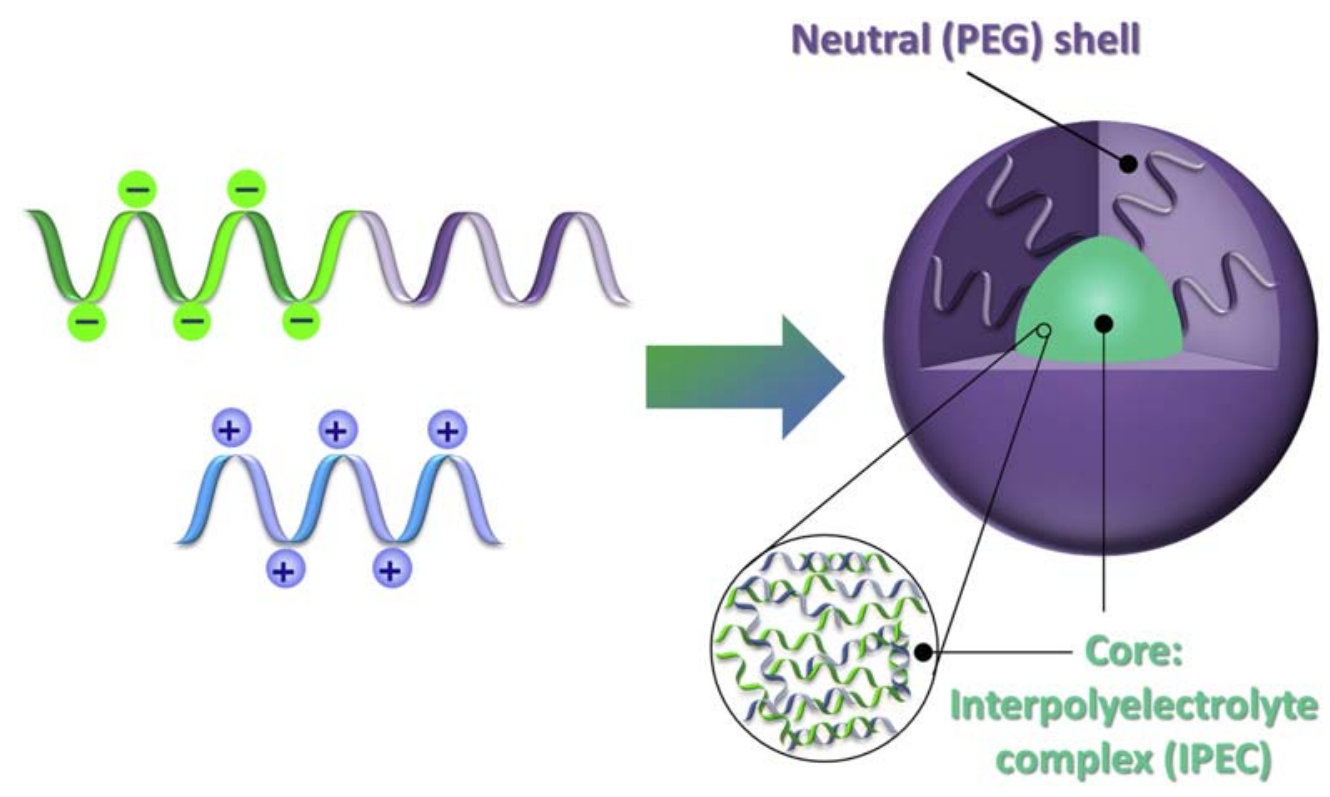

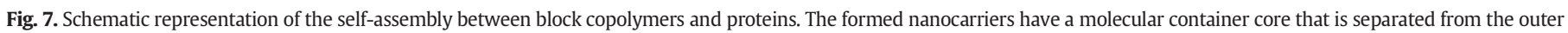
environment by a neutral shell. Adapted from [89]. 


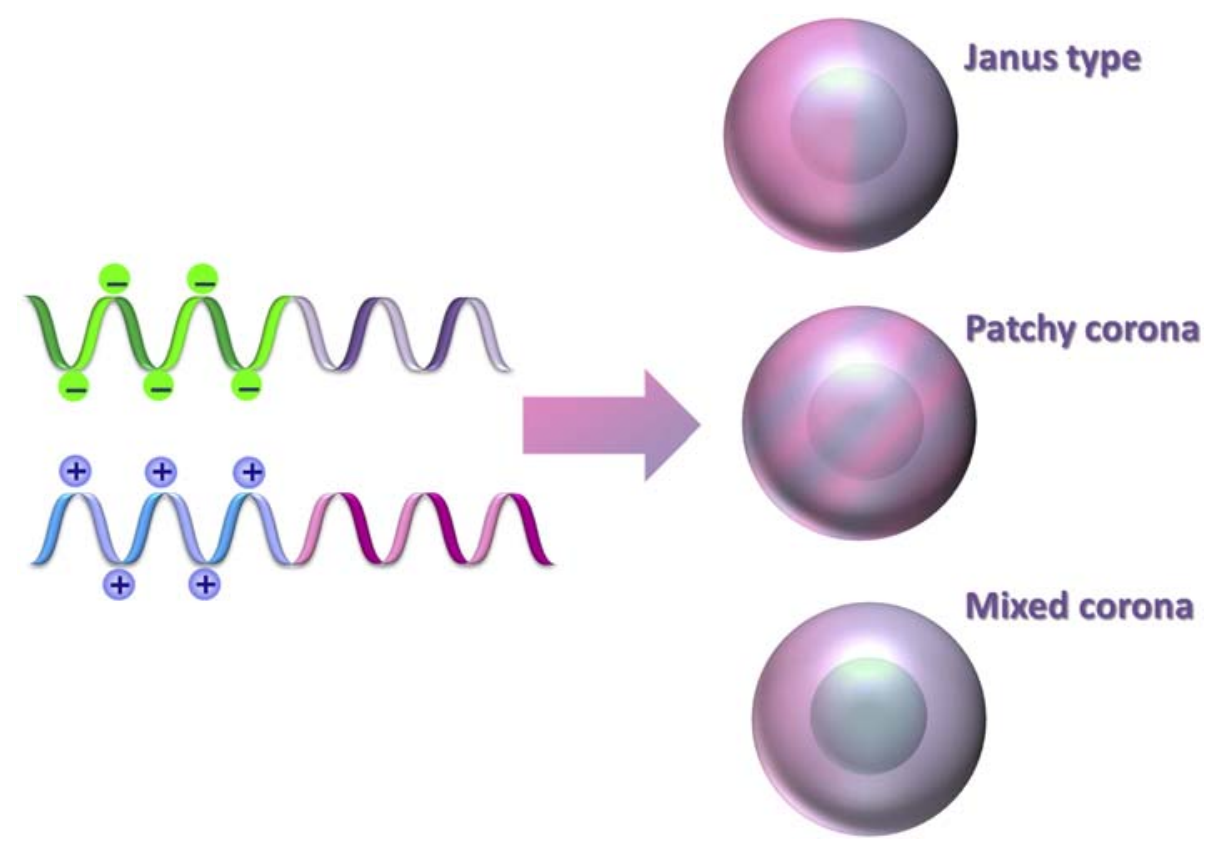

Fig. 8. Schematic representation of interpolyelectrolyte complexation between block copolymers with different non-ionic segments. Adapted from [111].

predictive and quantitative theoretical tools, including molecular dynamics and computational modelling, to self-assembled carriers is necessary to obtain insights into the interactions involved in the assembly/ disassembly and design carriers with optimized properties (enhanced stability and higher delivery efficiency). This is especially important for clinical applications where carriers with predictable properties are required. Such devices will not only advance the field of controlled release systems, but will also enable the development of a new generation of in vitro systems mimicking multiple aspects of living tissues.

\section{Acknowledgements}

H. S. Azevedo acknowledges the financial support of the European Union under the Marie Curie Career Integration Grant SuprHApolymers (PCIG14-GA-2013-631871). I. Pashkuleva is thankful to the Portuguese foundation for science and technology (IF/00032/2013) and to the European Union (REGPOT-2012-2013-1-316331).

\section{References}

[1] V.P. Torchilin, Multifunctional, stimuli-sensitive nanoparticulate systems for drug delivery, Nat. Rev. Drug Discov. 13 (2014) 813-827.

[2] D. Peters, M. Kastantin, V.R. Kotamraju, P.P. Karmali, K. Gujraty, M. Tirrell, E. Ruoslahti, Targeting atherosclerosis by using modular, multifunctional micelles, Proc. Natl. Acad. Sci. U. S. A. 106 (2009) 9815-9819.

[3] D.F. Bowenpope, T.W. Malpass, D.M. Foster, R. Ross, Platelet-derived growth-factor in vivo - levels, activity, and rate of clearance, Blood 64 (1984) 458-469.

[4] E.R. Edelman, M.A. Nugent, M.J. Karnovsky, Perivascular and intravenous administration of basic fibroblast growth-factor-vascular and solid organ deposition, Proc. Natl. Acad. Sci. U. S. A. 90 (1993) 1513-1517.

[5] S.J. Rymer, S.J. Tendler, C. Bosquillon, C. Washington, C.J. Roberts, Self-assembling peptides and their potential applications in biomedicine, Ther. Deliv. 2 (2011) 1043-1056.

[6] P. Tayalia, D.J. Mooney, Controlled growth factor delivery for tissue engineering, Adv. Mater. 21 (2009) 3269-3285.

[7] P.S. Lienemann, M.P. Lutolf, M. Ehrbar, Biomimetic hydrogels for controlled biomolecule delivery to augment bone regeneration, Adv. Drug Deliv. Rev. 64 (2012) 1078-1089.

[8] J.J. Rice, M.M. Martino, L. De Laporte, F. Tortelli, P.S. Briquez, J.A. Hubbell, Engineering the regenerative microenvironment with biomaterials, Adv. Healthcare Mater. 2 (2013) 57-71.

[9] A.M. Boulet, A.M. Moon, B.R. Arenkiel, M.R. Capecchi, The roles of Fgf4 and Fgf8 in limb bud initiation and outgrowth, Dev. Biol. 273 (2004) 361-372.

[10] D.M. Ornitz, P.J. Marie, FGF signaling pathways in endochondral and intramembranous bone development and human genetic disease, Genes Dev. 16 (2002) 1446-1465.
[11] N. Su, J. Min, L. Chen, Role of FGF/FGFR signaling in skeletal development and homeostasis: learning from mouse models, Bone Res. 2 (2014) 14003.

[12] P.C. Bessa, M. Casal, R.L. Reis, Bone morphogenetic proteins in tissue engineering: the road from the laboratory to the clinic, part I (basic concepts), J. Tissue Eng. Regen. Med. 2 (2008) 1-13.

[13] M. Samee, S. Kasugai, H. Kondo, K. Ohya, H. Shimokawa, S. Kuroda, Bone morphogenetic protein-2 (BMP-2) and vascular endothelial growth factor (VEGF) transfection to human periosteal cells enhances osteoblast differentiation and bone formation, J. Pharmacol. Sci. 108 (2008) 18-31.

[14] U. Mayr-Wohlfart, J. Waltenberger, H. Hausser, S. Kessler, K.P. Gunther, C. Dehio, W. Puhl, R.E. Brenner, Vascular endothelial growth factor stimulates chemotactic migration of primary human osteoblasts, Bone 30 (2002) 472-477.

[15] M. Orlandini, A. Spreafico, M. Bardelli, M. Rocchigiani, A. Salameh, S. Nucciotti, C. Capperucci, B. Frediani, S. Oliviero, Vascular endothelial growth factor-D activates VEGFR-3 expressed in osteoblasts inducing their differentiation, J. Biol. Chem. 281 (2006) 17961-17967.

[16] S. Yakar, H.W. Courtland, D. Clemmons, IGF-1 and bone: new discoveries from mouse models, J. Bone Miner. Res. 25 (2010) 2267-2276.

[17] S.F. Ahmed, C. Farquharson, The effect of GH and IGF1 on linear growth and skeletal development and their modulation by SOCS proteins, J. Endocrinol. 206 (2010) 249-259.

[18] E. Canalis, Growth factor control of bone mass, J. Cell. Biochem. 108 (2009) 769-777.

[19] L.N. Ramoshebi, T.N. Matsaba, J. Teare, L. Renton, J. Patton, U. Ripamonti, Tissue engineering: TGF-beta superfamily members and delivery systems in bone regeneration, Expert Rev. Mol. Med. 4 (2002) 1-11.

[20] G. Balooch, M. Balooch, R.K. Nalla, S. Schilling, E.H. Filvaroff, G.W. Marshall, S.J. Marshall, R.O. Ritchie, R. Derynck, T. Alliston, TGF-beta regulates the mechanical properties and composition of bone matrix, Proc. Natl. Acad. Sci. U. S. A. 102 (2005) 18813-18818.

[21] V. Vogel, M. Sheetz, Local force and geometry sensing regulate cell functions, Nat. Rev. Mol. Cell Biol. 7 (2006) 265-275.

[22] B. Trappmann, J.E. Gautrot, J.T. Connelly, D.G. Strange, Y. Li, M.L. Oyen, M.A. Cohen Stuart, H. Boehm, B. Li, V. Vogel, J.P. Spatz, F.M. Watt, W.T. Huck, Extracellularmatrix tethering regulates stem-cell fate, Nat. Mater. 11 (2012) 642-649.

[23] R.O. Hynes, The extracellular matrix: not just pretty fibrils, Science 326 (2009) 1216-1219.

[24] R. Flaumenhaft, D. Moscatelli, D.B. Rifkin, Heparin and heparan-sulfate increase the radius of diffusion and action of basic fibroblast growth-factor, J. Cell Biol. 111 (1990) 1651-1659.

[25] S. Amorim, R.A. Pires, D.S. da Costa, R.L. Reis, I. Pashkuleva, Interactions between exogenous FGF-2 and sulfonic groups: in situ characterization and impact on the morphology of human adipose-derived stem cells, Langmuir 29 (2013) 7983-7992.

[26] R. Goetz, M. Mohammadi, Exploring mechanisms of FGF signalling through the lens of structural biology, Nat. Rev. Mol. Cell Biol. 14 (2013) 166-180.

[27] W.P. Daley, S.B. Peters, M. Larsen, Extracellular matrix dynamics in development and regenerative medicine, J. Cell Sci. 121 (2008) 255-264.

[28] K. von der Mark, J. Park, S. Bauer, P. Schmuki, Nanoscale engineering of biomimetic surfaces: cues from the extracellular matrix, Cell Tissue Res. 339 (2010) 131-153.

[29] M.J. Dalby, N. Gadegaard, R.O. Oreffo, Harnessing nanotopography and integrinmatrix interactions to influence stem cell fate, Nat. Mater. 13 (2014) 558-569.

[30] R.A.A. Smith, K. Meade, C.E. Pickford, R.J. Holley, C.L.R. Merry, Glycosaminoglycans as regulators of stem cell differentiation, Biochem. Soc. Trans. 39 (2011) 383-387. 
[31] L. Gasimli, A.M. Hickey, B. Yang, G. Li, M. dela Rosa, A.V. Nairn, M.J. Kulik, J.S Dordick, K.W. Moremen, S. Dalton, R.J. Linhardt, Changes in glycosaminoglycan structure on differentiation of human embryonic stem cells towards mesoderm and endoderm lineages, Bba-Gen Subjects 1840 (2014) 1993-2003.

[32] J. Salbach, S. Kliemt, M. Rauner, T.D. Rachner, C. Goettsch, S. Kalkhof, M. von Bergen, S. Moller, M. Schnabelrauch, V. Hintze, D. Scharnweber, L.C. Hofbauer, The effect of the degree of sulfation of glycosaminoglycans on osteoclast function and signaling pathways, Biomaterials 33 (2012) 8418-8429.

[33] J. Salbach, T.D. Rachner, M. Rauner, U. Hempel, U. Anderegg, S. Franz, J.C. Simon, L.C. Hofbauer, Regenerative potential of glycosaminoglycans for skin and bone, J. Mol. Med. 90 (2012) 625-635 (Berl).

[34] I. Capila, R.J. Linhardt, Heparin-protein interactions, Angew. Chem. Int. Ed. 41 (2002) 391-412.

[35] G. Venkataraman, V. Sasisekharan, A.B. Herr, D.M. Ornitz, G. Waksman, C.L. Cooney, R. Langer, R. Sasisekharan, Preferential self-association of basic fibroblast growth factor is stabilized by heparin during receptor dimerization and activation, Proc. Natl. Acad. Sci. U. S. A. 93 (1996) 845-850.

[36] F.M. Zhang, Z.Q. Zhang, X.F. Lin, A. Beenken, A.V. Eliseenkova, M. Mohammadi, R.J. Linhardt, Compositional analysis of heparin/heparan sulfate interacting with fibroblast growth factor. fibroblast growth factor receptor complexes, Biochemistry 48 (2009) 8379-8386.

[37] A.B. Herr, D.M. Ornitz, R. Sasisekharan, G. Venkataraman, G. Waksman, Heparininduced self-association of fibroblast growth factor-alpha - evidence for two oligomerization processes, J. Biol. Chem. 272 (1997) 16382-16389.

[38] A.D. DiGabriele, I. Lax, D.I. Chen, C.M. Svahn, M. Jaye, J. Schlessinger, W.A. Hendrickson, Structure of a heparin-linked biologically active dimer of fibroblast growth factor, Nature 393 (1998) 812-817.

[39] M. Lyon, G. Rushton, J.T. Gallagher, The interaction of the transforming growth factor-beta s with heparin heparan sulfate is isoform-specific, J. Biol. Chem. 272 (1997) 18000-18006.

[40] W.J. Zhao, S.A. McCallum, Z.P. Xiao, F.M. Zhang, R.J. Linhardt, Binding affinities of vascular endothelial growth factor (VEGF) for heparin-derived oligosaccharides, Biosci. Rep. 32 (2012) 71-81.

[41] W.J. Fairbrother, M.A. Champe, H.W. Christinger, B.A. Keyt, M.A. Starovasnik, Solution structure of the heparin-binding domain of vascular endothelial growth factor, Struct. Fold. Des. 6 (1998) 637-648.

[42] D. Xu, M.M. Fuster, R. Lawrence, J.D. Esko, Heparan sulfate regulates VEGF(165)and VEGF(121)-mediated vascular hyperpermeability, J. Biol. Chem. 286 (2011) 737-745.

[43] T. Arai, A. Parker, W. Busby, D.R. Clemmons, Heparin, heparan-sulfate, and dermatan sulfate regulate formation of the insulin-like growth-factor-I and insulin-like growth factor-binding protein complexes, J. Biol. Chem. 269 (1994) 20388-20393.

[44] J. Lund, M.T. Sondergaard, C.A. Conover, M.T. Overgaard, Heparin-binding mechanism of the IGF2/IGF-binding protein 2 complex, J. Mol. Endocrinol. 52 (2014) 345-355.

[45] S. Boddohi, M.J. Kipper, Engineering nanoassemblies of polysaccharides, Adv. Mater. 22 (2010) 2998-3016.

[46] G.A. Hudalla, W.L. Murphy, Biomaterials that regulate growth factor activity via bioinspired interactions, Adv. Funct. Mater. 21 (2011) 1754-1768.

[47] J.K. Kim, J. Anderson, H.W. Jun, M.A. Repka, S. Jo, Self-assembling peptide amphiphile-based nanofiber gel for bioresponsive cisplatin delivery, Mol. Pharm. 6 (2009) 978-985.

[48] Y. Zhao, M. Tanaka, T. Kinoshita, M. Higuchi, T.W. Tan, Nanofibrous scaffold from self-assembly of beta-sheet peptides containing phenylalanine for controlled release, J. Control. Release 142 (2010) 354-360.

[49] A.J. van Hell, M.M. Fretz, D.J.A. Crommelin, W.E. Hennink, E. Mastrobattista, Peptide nanocarriers for intracellular delivery of photosensitizers, J. Control. Release 141 (2010) 347-353.

[50] X.H. Yan, Q. He, K.W. Wang, L. Duan, Y. Cui, J.B. Li, Transition of cationic dipeptide nanotubes into vesicles and oligonucleotide delivery, Angew. Chem. Int. Ed. 46 (2007) 2431-2434

[51] H.F. Liu, J.A. Chen, Q. Shen, W. Fu, W. Wu, Molecular insights on the cyclic peptide nanotube-mediated transportation of antitumor drug 5-fluorouracil, Mol. Pharm. 7 (2010) 1985-1994

[52] Y. Shi, H. Zhou, X.L. Zhang, J.Y. Wang, J.F. Long, Z.M. Yang, D. Ding, Self-assembling choline mimicks with enhanced binding affinities to C-LytA protein, Sci. Rep 4 (2014).

[53] A.G. Cheetham, P. Zhang, Y.-a. Lin, L.L. Lock, H. Cui, Supramolecular nanostructures formed by anticancer drug assembly, J. Am. Chem. Soc. 135 (2013) 2907-2910.

[54] J.F. Miravet, B. Escuder, M.D. Segarra-Maset, M. Tena-Solsona, I.W. Hamley, A. Dehsorkhi, V. Castelletto, Self-assembly of a peptide amphiphile: transition from nanotape fibrils to micelles, Soft Matter 9 (2013) 3558-3564.

[55] A. Ghosh, M. Haverick, K. Stump, X.Y. Yang, M.F. Tweedle, J.E. Goldberger, Finetuning the pH trigger of self-assembly, J. Am. Chem. Soc. 134 (2012) 3647-3650.

[56] D. Kalafatovic, M. Nobis, N. Javid, P.W.J.M. Frederix, K.I. Anderson, B.R. Saunders, R.V. Ulijn, MMP-9 triggered micelle-to-fibre transitions for slow release of doxorubicin, Biomater. Sci. 3 (2015) 246-249.

[57] N. Sarkar, J. Banerjee, A.J. Hanson, A.I. Elegbede, T. Rosendahl, A.B. Krueger, A.L. Banerjee, S. Tobwala, R.Y. Wang, X.N. Lu, S. Mallik, D.K. Srivastava, Matrix metalloproteinase-assisted triggered release of liposomal contents, Bioconjug. Chem. 19 (2008) 57-64.

[58] Y.A. Lin, Y.C. Ou, A.G. Cheetham, H.G. Cui, Rational design of MMP degradable peptide-based supramolecular filaments, Biomacromolecules 15 (2014) 1419-1427.
[59] M.J. Webber, C.J. Newcomb, R. Bitton, S.I. Stupp, Switching of self-assembly in a peptide nanostructure with a specific enzyme, Soft Matter 7 (2011) 9665-9672.

[60] A. Dehsorkhi, I.W. Hamley, J. Seitsonen, J. Ruokolainen, Tuning self-assembled nanostructures through enzymatic degradation of a peptide amphiphile, Langmuir 29 (2013) 6665-6672.

[61] G.A. Hudalla, T. Sun, J.Z. Gasiorowski, H.F. Han, Y.F. Tian, A.S. Chong, J.H. Collier, Gradated assembly of multiple proteins into supramolecular nanomaterials, Nat. Mater. 13 (2014) 829-836.

[62] A.E. Mercado, J.Y. Ma, X.Z. He, E. Jabbari, Release characteristics and osteogenic activity of recombinant human bone morphogenetic protein-2 grafted to novel selfassembled poly(lactide-co-glycolide fumarate) nanoparticles, J. Control. Release 140 (2009) 148-156.

[63] S. Matsumura, S. Uemura, H. Mihara, Construction of biotinylated peptide nanotubes for arranging proteins, Mol. Biosyst 1 (2005) 146-148.

64] R.E. Miller, P.W. Kopesky, A.J. Grodzinsky, Growth factor delivery through selfassembling peptide scaffolds, Clin. Orthop. Relat. Res. 469 (2011) 2716-2724.

[65] M.E. Davis, P.C.H. Hsieh, T. Takahashi, Q. Song, S.G. Zhang, R.D. Kamm, A.J. Grodzinsky, P. Anversa, R.T. Lee, Local myocardial insulin-like growth factor 1 (IGF-1) delivery with biotinylated peptide nanofibers improves cell therapy for myocardial infarction, Proc. Natl. Acad. Sci. U. S. A. 103 (2006) 8155-8160.

[66] P.C.H. Hsieh, M.E. Davis, J. Gannon, C. MacGillivray, R.T. Lee, Controlled delivery of PDGF-BB for myocardial protection using injectable self-assembling peptide nanofibers, J. Clin. Invest. 116 (2006) 237-248.

[67] L. Macri, D. Silverstein, R.A.F. Clark, Growth factor binding to the pericellular matrix and its importance in tissue engineering, Adv. Drug Deliv. Rev. 59 (2007) 1366-1381.

[68] R. Mammadov, B. Mammadov, M.O. Guler, A.B. Tekinay, Growth factor binding on heparin mimetic peptide nanofibers, Biomacromolecules 13 (2012) 3311-3319.

[69] K. Rajangam, H.A. Behanna, M.J. Hui, X.Q. Han, J.F. Hulvat, J.W. Lomasney, S.I. Stupp, Heparin binding nanostructures to promote growth of blood vessels, Nano Lett. 6 (2006) 2086-2090.

[70] L.W. Chow, R. Bitton, M.J. Webber, D. Carvajal, K.R. Shull, A.K. Sharma, S.I. Stupp, A bioactive self-assembled membrane to promote angiogenesis, Biomaterials 32 (2011) 1574-1582.

[71] L.W. Chow, L.J. Wang, D.B. Kaufman, S.I. Stupp, Self-assembling nanostructures to deliver angiogenic factors to pancreatic islets, Biomaterials 31 (2010) 6154-6161.

[72] J.C. Stendahl, L.J. Wang, L.W. Chow, D.B. Kaufman, S.I. Stupp, Growth factor delivery from self-assembling nanofibers to facilitate islet transplantation, Transplantation 86 (2008) 478-481.

[73] M.M. Martino, F. Tortelli, M. Mochizuki, S. Traub, D. Ben-David, G.A. Kuhn, R. Muller, E. Livne, S.A. Eming, J.A. Hubbell, Engineering the growth factor microenvironment with fibronectin domains to promote wound and bone tissue healing, Sci. Transl. Med. 3 (2011).

[74] J. Huang, B. Ru, P. Zhu, F. Nie, J. Yang, X. Wang, P. Dai, H. Lin, F.-B. Guo, N. Rao, MimoDB 2.0: a mimotope database and beyond, Nucleic Acids Res. 40 (2012) D271-D277.

[75] R.N. Shah, N.A. Shah, M.M. Del Rosario Lim, C. Hsieh, G. Nuber, S.I. Stupp, Supramolecular design of self-assembling nanofibers for cartilage regeneration, Proc. Natl. Acad. Sci. U. S. A. 107 (2010) 3293-3298.

[76] L.Y. Li, J.R. Klim, R. Derda, A.H. Courtney, L.L. Kiessling, Spatial control of cell fate using synthetic surfaces to potentiate TGF-beta signaling, Proc. Natl. Acad. Sci. U. S. A. 108 (2011) 11745-11750.

[77] S.S. Lee, E.L. Hsu, M. Mendoza, J. Ghodasra, M.S. Nickoli, A. Ashtekar, M. Polavarapu, J. Babu, R.M. Riaz, J.D. Nicolas, D. Nelson, S.Z. Hashmi, S.R. Kaltz, J.S. Earhart, B.R. Merk, J.S. McKee, S.F. Bairstow, R.N. Shah, W.K. Hsu, S.I. Stupp, Gel scaffolds of BMP-2-binding peptide amphiphile nanofibers for spinal arthrodesis, Adv. Healthcare Mater. 4 (2015) 131-141.

[78] C.C. Lin, K.S. Anseth, Controlling affinity binding with peptide-functionalized poly(ethylene glycol) hydrogels, Adv. Funct. Mater. 19 (2009) 2325-2331.

[79] A. Yayon, D. Aviezer, M. Safran, J.L. Gross, Y. Heldman, S. Cabilly, D. Givol, E. Katchalskikatzir, Isolation of peptides that inhibit binding of basic fibroblast growth-factor to its receptor from a random phage-epitope library, Proc. Natl. Acad. Sci. U. S. A. 90 (1993) 10643-10647.

[80] T. Terada, M. Mizobata, S. Kawakami, Y. Yabe, F. Yamashita, M. Hashida, Basic fibroblast growth factor-binding peptide as a novel targeting ligand of drug carrier to tumor cells, J. Drug Target. 14 (2006) 536-545.

[81] H.A. Behanna, J.J.J.M. Donners, A.C. Gordon, S.I. Stupp, Coassembly of amphiphiles with opposite peptide polarities into nanofibers, J. Am. Chem. Soc. 127 (2005) 1193-1200.

82] R.J. Seelbach, P. Fransen, D. Pulido, M. D'Este, F. Duttenhoefer, S. Sauerbier, T.M. Freiman, P. Niemeyer, F. Albericio, M. Alini, M. Royo, A. Mata, D. Eglin, Injectable hyaluronan hydrogels with peptide-binding dendrimers modulate the controlled release of BMP-2 and TGF-B1, Macromol. Biosci. 15 (2015) 1035-1044.

[83] M.M. Martino, P.S. Briquez, A. Ranga, M.P. Lutolf, J.A. Hubbell, Heparin-binding domain of fibrin(ogen) binds growth factors and promotes tissue repair when incorporated within a synthetic matrix, Proc. Natl. Acad. Sci. U. S. A. 110 (2013) $4563-4568$.

[84] M.M. Amiji, Polimeric Gene delivery: Principles and Applications, CRC Press, Boca Raton, Florida, 2005.

[85] K.N. Bakeev, V.A. Izumrudov, A.B. Zezin, V.A. Kabanov, Kinetics and mechanism of reactions of the formation of polyelectrolytic complexes, Dokl. Akad. Nauk SSSR 299 (1988) 1405-1408

[86] C. Schatz, A. Domard, C. Viton, C. Pichot, T. Delair, Versatile and efficient formation of colloids of biopolymer-based polyelectrolyte complexes, Biomacromolecules 5 (2004) 1882-1892. 
[87] P.M. Lopez-Perez, R.M.P. da Silva, I. Pashkuleva, F. Parra, R.L. Reis, J. San Roman, Hydrophobic-electrostatic balance driving the LCST offset aggregation-redissolution behavior of $\mathrm{N}$-alkylacrylamide-based ionic terpolymers, Langmuir 26 (2010) 5934-5941.

[88] S. Boddohi, N. Moore, P.A. Johnson, M.J. Kipper, Polysaccharide-based polyelectrolyte complex nanoparticles from chitosan, heparin, and hyaluronan, Biomacromolecules 10 (2009) 1402-1409.

[89] R. Novoa-Carballal, C. Silva, S. Moller, M. Schnabelrauch, R.L. Reis, I. Pashkuleva, Tunable nano-carriers from clicked glycosaminoglycan block copolymers, J. Mater. Chem. B 2 (2014) 4177-4184.

[90] M. Huang, S.N. Vitharana, L.J. Peek, T. Coop, C. Berkland, Polyelectrolyte complexes stabilize and controllably release vascular endothelial growth factor, Biomacromolecules 8 (2007) 1607-1614.

[91] M. Goldberg, R. Langer, X.Q. Jia, Nanostructured materials for applications in drug delivery and tissue engineering, J. Biomater. Sci. Polym. Ed. 18 (2007) 241-268.

[92] P.C. Bessa, E.R. Balmayor, H.S. Azevedo, S. Nurnberger, M. Casal, M. van Griensven, R.L. Reis, H. Redl, Silk fibroin microparticles as carriers for delivery of human recombinant BMPs. Physical characterization and drug release, J. Tissue Eng. Regen. Med. 4 (2010) 349-355.

[93] V.E. Santo, M.E. Gomes, J.F. Mano, R.L. Reis, Chitosan-chondroitin sulphate nanoparticles for controlled delivery of platelet lysates in bone regenerative medicine, J. Tissue Eng. Regen. Med. 6 (2012) s47-s59.

[94] B.J.Zern, H.H. Chu, Y.D. Wang, Control growth factor release using a self-assembled [polycation:heparin] complex, Plos One 5 (2010) e11017.

[95] H.H. Chu, J. Gao, C.W. Chen, J. Huard, Y.D. Wang, Injectable fibroblast growth factor2 coacervate for persistent angiogenesis, Proc. Natl. Acad. Sci. U. S. A. 108 (2011) 13444-13449.

[96] L.W. Place, M. Sekyi, M.J. Kipper, Aggrecan-mimetic, glycosaminoglycan-containing nanoparticles for growth factor stabilization and delivery, Biomacromolecules 15 (2014) 680-689.

[97] M. Huang, C. Berkland, Controlled release of repifermin (R) from polyelectrolyte complexes stimulates endothelial cell proliferation, J. Pharm. Sci. 98 (2009) 268-280.

[98] Q. Tan, H. Tang, J.G. Hu, Y.R. Hu, X.M. Zhou, Y.M. Tao, Z.S. Wu, Controlled release of chitosan/heparin nanoparticle-delivered VEGF enhances regeneration of decellularized tissue-engineered scaffolds, Int. J. Nanomedicine 6 (2011) 929-942.
[99] C. Schatz, J.M. Lucas, C. Viton, A. Domard, C. Pichot, T. Delair, Formation and properties of positively charged colloids based on polyelectrolyte complexes of biopolymers, Langmuir 20 (2004) 7766-7778.

[100] R. Novoa-Carballal, D.V. Pergushov, A.H.E. Muller, Interpolyelectrolyte complexes based on hyaluronic acid-block-poly(ethylene glycol) and poly-L-lysine, Soft Matter 9 (2013) 4297-4303.

[101] Y. Chen, V.J. Mohanraj, J.E. Parkin, Chitosan-dextran sulfate nanoparticles for delivery of an anti-angiogenesis peptide, Lett. Pept. Sci. 10 (2003) 621-629.

[102] J.S. Lee, J.W. Bae, Y.K. Joung, S.J. Lee, D.K. Han, K.D. Park, Controlled dual release of basic fibroblast growth factor and indomethacin from heparin-conjugated polymeric micelle, Int. J. Pharm. 346 (2008) 57-63.

[103] T. Miller, M.C. Goude, T.C. McDevitt, J.S. Temenoff, Molecular engineering of glycosaminoglycan chemistry for biomolecule delivery, Acta Biomater. 10 (2014) 1705-1719.

[104] K. Kataoka, G.S. Kwon, M. Yokoyama, T. Okano, Y. Sakurai, Block-copolymer micelles as vehicles for drug delivery, J. Control. Release 24 (1993) 119-132.

[105] S.M. Moghimi, A.C. Hunter, J.C. Murray, Long-circulating and target-specific nanoparticles: theory to practice, Pharmacol. Rev. 53 (2001) 283-318.

[106] B. Gonzalez, M. Colilla, M. Vallet-Regi, Time-delayed release of bioencapsulates: a novel controlled delivery concept for bone implant technologies, Chem. Mater. 20 (2008) 4826-4834.

[107] A.V. Kabanov, T.K. Bronich, V.A. Kabanov, K. Yu, A. Eisenberg, Soluble stoichiometric complexes from poly(N-ethyl-4-vinylpyridinium) cations and poly(ethylene oxide)-block-polymethacrylate anions, Macromolecules 29 (1996) 6797-6802.

[108] A. Harada, K. Kataoka, Chain length recognition: core-shell supramolecular assembly from oppositely charged block copolymers, Science 283 (1999) 65-67.

[109] S. Katayose, K. Kataoka, Water-soluble polyion complex associates of DNA and poly(ethylene glycol)-poly(L-lysine) block copolymer, Bioconjug. Chem. 8 (1997) 702-707.

[110] R. Novoa-Carballal, A.H.E. Muller, Synthesis of polysaccharide-b-PEG block copolymers by oxime click, Chem. Commun. 48 (2012) 3781-3783.

[111] D.V. Pergushov, A.H.E. Muller, F.H. Schacher, Micellar interpolyelectrolyte complexes, Chem. Soc. Rev. 41 (2012) 6888-6901. 